\title{
Dictynna
}

Dictynna

Revue de poétique latine

5 | 2008

Varia

\section{Teseo, la clementia e la punizione dei tiranni: esemplarità e pessimismo nel finale della Tebaide}

Federica Bessone

\section{(2) OpenEdition}

Journals

Edizione digitale

URL: http://journals.openedition.org/dictynna/200

DOI: 10.4000/dictynna.200

ISSN: 1765-3142

\section{Notizia bibliografica digitale}

Federica Bessone, «Teseo, la clementia e la punizione dei tiranni: esemplarità e pessimismo nel finale della Tebaide », Dictynna [En ligne], 5 | 2008, mis en ligne le 25 novembre 2010, consulté le 10 septembre 2020. URL : http://journals.openedition.org/dictynna/200 ; DOI : https://doi.org/10.4000/ dictynna. 200

Questo documento è stato generato automaticamente il 10 settembre 2020.

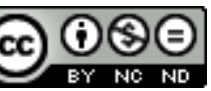

Les contenus des la revue Dictynna sont mis à disposition selon les termes de la Licence Creative Commons Attribution - Pas d'Utilisation Commerciale - Pas de Modification 4.0 International. 


\title{
Teseo, la clementia e la punizione dei tiranni: esemplarità e pessimismo nel finale della Tebaide
}

\author{
Federica Bessone
}

\section{Interpretazione del finale, interpretazioni della 'Tebaide'}

1 Nel 1996 un importante articolo di Susanna Morton Braund richiamava l'attenzione sulla chiusa della Tebaide e ne proponeva un'interpretazione provocatoriamente ottimista. In controtendenza rispetto a letture pessimistiche e sovversive, del finale e del poema, che si andavano affermando, la studiosa indicava nell'intervento di Teseo l'estremo tentativo di Stazio di imporre una soluzione al conflitto tebano e una chiusura epica al racconto: eroe esterno nel ruolo di deus ex machina, nella visione della Braund il sovrano ateniese, romanizzato, chiude la guerra civile come un generale trionfatore e ristabilisce la pace affermando il valore imperiale romano della clemenza. Il dibattito sul poema staziano - veniva osservato - tendeva già da tempo a riprodurre, nella polarizzazione tra ottimisti e pessimisti, le vicende del dibattito critico sull'Eneide, con la contrapposizione tra augustei e anti-augustei, fra scuola europea e 'scuola di Harvard'; schierandosi apertamente con gli ottimisti, la stessa studiosa invocava l'interpretazione virgiliana di Francis Cairns (1989) e la sua costruzione di Enea vittorioso come modello di Augusto.

2 In quegli anni gli studi staziani attraversavano una fase di profondo mutamento. La lettura della Tebaide in chiave stoica, come epica positiva e "della redenzione", affermata all'inizio degli anni '70 dal saggio di Vessey, aveva ceduto il passo a visioni spesso fortemente negative del poema, talvolta orientate in senso spiccatamente politico e determinate a rintracciare, in quest'epica dominata da forze distruttive, una critica indiretta al potere imperiale o un velato, ma circostanziato e puntuale atto d'accusa contro la casa flavia ${ }^{1}$. Il personaggio di Teseo, innalzato da Vessey a modello 
ideale di re clemente e giusto, veniva ora sottoposto a una severa revisione critica, fatto oggetto di aspre accuse e trasformato in eroe negativo, capace di gettare ombra sulla costruzione solo in apparenza rassicurante della chiusa.

3 Il ruolo della clementia e di Teseo nel finale andava così assumendo, sempre di più, un'importanza centrale per l'interpretazione dell'intero poema. All'eroe pacificatore, combattente per una giusta causa e paradigma di valori imperiali ${ }^{2}$, si contrapponeva un eroe violento e smanioso di guerra, carico di un passato e di un futuro mitico imbarazzanti, costruito come ritratto in nero di Domiziano: era questo (per citare $\mathrm{i}$ nomi più influenti) il Teseo di Ahl e di Dominik ${ }^{3}$. Tra quei due estremi dello spettro critico, interpretazioni 'pluralistiche', sensibili alle tensioni irrisolte dell'epos staziano, riconoscevano lo sforzo di risoluzione della chiusa, ma mettevano in luce potenziali, disturbanti ambiguità di Teseo: così, ad esempio, la rapida trattazione di Hardie, problematica e stimolante, nel saggio sui successori epici di Virgilio ${ }^{4}$. La giustificazione dell'impresa ateniese dichiarata in forma esplicita dal testo veniva ora lasciata in secondo piano (come insufficiente e inattendibile, o forse come fuori moda ed inutilmente ingombrante); accuse e sospetti facevano emergere modalità di costruzione del personaggio in grado di smentire quell'ottimismo di superficie: il bellicismo precipitoso dell'azione, le allusioni a episodi meno luminosi nella carriera dell'eroe, le similitudini ambigue impiegate per caratterizzarlo.

Il periodo successivo all'intervento della Braund ha visto riproporsi quelle divisioni in forme nuove (e meno nuove), con un acuirsi del dissenso, ma con un progresso e un approfondimento della discussione. Pessimisti e sovversivi ad oltranza hanno ribadito le loro tesi, nel frattempo ripetute da più parti ed arricchite di altri argomenti, soprattutto in contributi di area anglo-americana ${ }^{5}$ l'interpretazione in chiave politica ha tentato, ad esempio, di allineare Stazio alla critica radicale della clementia Caesaris espressa da Lucano ${ }^{6}$, mentre letture negative orientate in senso 'privato' hanno messo l'accento sulla componente del lamento che domina il racconto e sugli aspetti della sofferenza e del lutto femminile rappresentati nel poema ${ }^{7}$. Per contro, un nuovo slancio alla tendenza ottimista è stato impresso, con esito vario, soprattutto dalla scuola francese: insieme a quella di Teseo, si è presa in esame la celebrazione della clementia nel poema, ora interpretandola in senso non politico ma esclusivamente morale, come affermazione di humanitas ${ }^{8}$, ora accentuandone invece il valore ideologico-imperiale e mettendo in parallelo - o addirittura facendo coincidere tout court - esaltazione della clementia di Teseo nella Tebaide ed esaltazione della clementia di Domiziano nelle Silvae ${ }^{9}$.

Nel 2004 il commento al libro XII di Karla Pollmann ha messo a disposizione uno strumento prezioso per lo studio del finale e un'introduzione equilibrata ai problemi principali: ma è sintomatico che esso rifletta, in alcune oscillazioni di giudizio, i contrasti di un panorama critico inquieto ${ }^{10}$. Le recentissime monografie di McNelis e di Ganiban (incentrate sul rapporto di Stazio con la tradizione callimachea e con l'Eneide) respingono una lettura della Tebaide in senso sovversivo e ostile alla casa flavia, ma propongono entrambe, con accenti diversi, una visione problematica del finale. McNelis riconosce nel trionfo di Teseo, modellato su quello di Augusto nell'ottavo libro dell' Eneide, una celebrazione indiretta della restaurazione flavia, modellatasi a sua volta su quella augustea: ma mostra che, nella visione di Stazio, la pace fragile seguita alla guerra civile non è definitiva, e non riscatta le sofferenze dei singoli; Teseo appare ancora carico di ambiguità, alla luce della tradizione catulliana; soprattutto, l'eroe viene dissociato dalla Clementia, che offrirebbe nel poema - essa sì - una soluzione e una 
speranza di pace, ma una soluzione di carattere privato, rivolta all'individuo e indipendente dallo stato ${ }^{11}$. Più problematico ancora, il Teseo di Ganiban "è uno dei personaggi più disturbanti e trasgressivi dell'epos", preda di passioni e insofferente dei limiti come tutti i sovrani della Tebaide (da Edipo a Creonte), mosso da una clementia che (all'opposto dell'ideale senecano) ha in sé la componente irrazionale, e dunque condannabile, della misericordia: insomma, modello di buon re solo nei limiti della visione totalmente negativa della regalità offerta dalla Tebaide (nella sua revisione critica dell'Eneide) ${ }^{12}$.

6 Molte, come si vede, sono le questioni da affrontare. Come parte di un lavoro più ampio che sto conducendo sulla Tebaide, e di cui ho anticipato altrove qualche argomento, vorrei qui richiamare l'attenzione su alcuni aspetti che mi sembrano utili alla discussione. Una premessa va fatta. La lettura sovversiva della Tebaide come epica contro l'impero, che sorregge ed orienta alcune visioni radicalmente negative del finale, si scontra innanzi tutto, a mio parere, con una difficoltà di ordine generale: la difficoltà di attribuire un ruolo plausibile di opposizione a un poeta che si autorappresenta come sostanzialmente integrato, e al tempo stesso determinato ad affermare un proprio spazio di autonomia; e che mostra di concepire genere epico e poesia d'occasione come impegno in una funzione culturale consapevolmente inquadrata nella società imperiale di età flavia. L'interpretazione dell'opera di Stazio che meglio mi sembra rendere conto, allo stesso tempo, della Tebaide e delle Silvae è quella di un negoziato complesso col potere imperiale, un equilibrio delicato di rapporti in cui la poesia riceve riconoscimenti e pretende attenzione, asseconda e promuove nel suo stesso interesse - un'immagine di armoniosa composizione dello stato: non si fa solo cassa di risonanza del discorso ufficiale, ma rivendica un ruolo creativo nell'elaborare l'ideologia del principato, una funzione essenziale nella formazione culturale dei ceti elevati (oltre che un compito di nobilitazione letteraria degli ambienti legati alla corte), forse addirittura un ruolo di coscienza critica del potere ${ }^{13}$.

7 L'epica di Stazio (prima dell'esperimento 'evasivo' dell'Achilleide) dichiara apertamente la sua aspirazione a ricoprire un ruolo canonico nella cultura romana, come quello da tempo riconosciuto all'Eneide. Nell'epilogo della Tebaide ${ }^{14}$ il poeta si rivolge a un pubblico composto dal sovrano e dai lettori (contemporanei e futuri) e davanti all'uno e agli altri - ma, soprattutto, mettendo l'uno di fronte agli altri - rivendica nei confronti di entrambi un ruolo forte, la responsabilità dell'educazione nazionale e forse, implicitamente, quella di un'educazione' del principe. Parlare del potere e (indirettamente) al potere, di fronte ai sudditi e al sovrano insieme: questo mi pare l'intento della Tebaide; nel congedarla, il poeta chiama non solo se stesso, ma anche gli elementi diversi del suo pubblico, alle responsabilità di cui il racconto epico li ha investiti, facendoli assistere ad una vicenda esemplare. Iam te magnanimus dignatur noscere Caesar, / Itala iam studio discit memoratque iuventus (12, 814-5): il gesto ambizioso dell'autore epico lega il sovrano a un'opera che lo riguarda, che i suoi sudditi mandano a memoria, e che i posteri giudicheranno anche in relazione a lui (12, 812-3 iam certe praesens tibi Fama benignum / stravit iter coepitque novam monstrare futuris). Le parole, e le 'persone', dell'epilogo richiamano non a caso un luogo forte del poema, e uno tra i più scopertamente didascalici: il commento d'autore al duello fratricida, che fa del cuore del racconto un exemplum dei mali del potere, e come tale lo offre alla meditazione del pubblico, dei posteri, dei potenti; 'un mito da dimenticare' per l'orrore che suscita, ma un monito incancellabile che in realtà tutti, e soprattutto i "re", dovranno per sempre, 
grazie al racconto epico, ricordare: monstrumque infame futuris / excidat, et soli memorent haec proelia reges $(11,578-9)$.

Chiamare in causa, nel congedo, il lettore imperiale e il pubblico dei lettori, usando l'uno per accreditarsi agli occhi dell'altro, è una mossa abile da parte di Stazio, che ricava dalla doppia destinazione un duplice vantaggio. Esibire di fronte ai lettori il favore dell'imperatore verso la propria opera è una trovata pubblicitaria vincente, ben sfruttata anche da Marziale ${ }^{15}$. Di più. Per un poeta che si presenta come il nuovo Virgilio in cerca di un nuovo Augusto, esibire di fronte al sovrano il proprio successo e la propria speranza di fama futura è più di un'autopromozione, è un'affermazione del potere della poesia - della grande poesia epica - di condizionare, sia pure in forma indiretta, il potere politico: significa tenerlo ambiziosamente come sotto ricatto, esercitare su di esso una pressione morale attraverso la presa sul pubblico, assumere nei suoi confronti agli occhi dei lettori, se non una impossibile funzione di controllo, almeno un impegno riconosciuto di coscienza critica.

Quello della Tebaide è un progetto audace e potenzialmente rischioso: comporre un poema epico su un mito di potere, slegato dalla storia romana ma carico di valenze politiche, e farne quasi uno speculum principis, o almeno una riflessione sull'autocrazia (sui suoi usi ed abusi) rivolta a un pubblico che ne ha esperienza diretta. Assumere l'autorità della voce epica, insomma, per riflettere e far riflettere sulla natura e sui pericoli del potere assoluto, commentando e sollecitando un giudizio su opposti modelli di sovranità: Stazio può intraprendere un programma così impegnativo stando al riparo di una tradizione familiare di lealismo, di una condizione sociale abbastanza modesta per non destare di per sé sospetti, e insieme facendosi forte di un ruolo pubblico, via via riconosciuto, come poeta professionale.

Lealismo imperiale e ambizione educativa, nei confronti delle élites e del principe stesso: questo complesso di atteggiamenti trova un modello nella figura del padre costruita da Stazio in Silvae 5, 3. Significativo è il passo che accosta in sequenza, e in continuità ideale, l'attività del padre come educatore della classe senatoria e cantore della casa flavia con l'attività poetica di Stazio fruita dall'aristocrazia romana ${ }^{16}$. Subito dopo aver rievocato, della figura paterna, l'insegnamento impartito ai giovani aristocratici (Romuleam stirpem proceresque futuros / instruis), l'istruzione religiosa di Domiziano fanciullo (sub te [...] crevit et inde sacrum didicit puer) ${ }^{17}$, la composizione, sul tema della guerra civile, di una poesia epica gradita al principe e ai Latii proceres (civilis Erinys [...] tu [...] concinis [...] mirantur Latii proceres ultorque deorum / Caesar), Stazio ricorda le recitazioni della propria poesia di fronte ai Latii patres sotto gli occhi compiaciuti e commossi del padre, scomparso troppo presto per vederlo premiato dall'imperatore: vv. 215-9 ...qualis eras, Latios quotiens ego carmine patres / mulcerem felixque tui spectator adesses / muneris, heu quali confundens gaudia fletu / vota piosque metus inter laetumque pudorem! / quam tuus ille dies, quam non mihi gloria maior! ${ }^{18}$. Il figlio dichiara così di raccogliere l'eredità del padre, mentre dimostra l'ambizione e l'orgoglio di superarlo. Se l'epicedio configura le linee di una tradizione familiare, l'epilogo della Tebaide conferma che Stazio ha assunto su di sé un ruolo di educatore della Itala iuventus, riconosciuto dal potere imperiale e svolto ora attraverso la propria stessa poesia. Nell'autorappresentazione di Stazio come poeta, la continuità con la figura paterna, con il suo ruolo di formatore delle élites e di cantore epico accreditato dalla casa flavia, è un elemento centrale; e la continuità riguarda, in certa misura, persino la scelta del tema e della forma poetica: quasi che la Tebaide, nel cantare di fronte 
all'imperatore un mito di guerra civile e di restaurazione dell'ordine, potesse apparire come la prosecuzione con altri mezzi dell'occasionale opera paterna, un proiettare su larga scala il racconto della civilis Erinys da cui era emerso il potere dei Flavi.

11 Ma il progetto della Tebaide è assai più ambizioso e complesso. Questa è una poesia che (a differenza del De bello Germanico) si tiene volutamente a distanza dalla celebrazione diretta - la recusatio lo dichiara - e che ricava per sé, nella dimensione grande dell'epos mitologico, uno spazio di indipendenza ${ }^{19}$. Il racconto miticoparla per figura: può suggerire analogie, scongiurare identificazioni, costruire modelli; non celebra o condanna apertamente, sembra piuttosto ammonire il potere politico, mentre fa mostra di assecondarlo (una strategia dell'ambiguità ben nota alla letteratura di corte $\mathrm{e}$ panegiristica). La scelta del mito appare come la scelta di una distanza di sicurezza, da cui parlare con relativa libertà di temi forti ed attuali come sovranità e tirannide; ma l'assunzione della voce epica, e della sua autorità, è al tempo stesso, per Stazio, la conquista di una posizione di forza: una rivendicazione della centralità culturale tradizionalmente riconosciuta a questo genere poetico.

Ancora un'osservazione preliminare. La forma della Tebaide inscrive in sé la coscienza di una crisi, letteraria e ideologica insieme. La narrazione del mito si dispone in un dittico, polarizzato ed asimmetrico: a undici libri di tragedia della tirannide si contrappone infine, senza riuscire a riscattarli, l'apparizione di una regalità clemente. Questa frattura della forma è essenziale al senso della Tebaide: è dal fondo del pessimismo sulla realtà del potere assoluto che il racconto di Stazio fa emergere una proposta positiva e uno sforzo di ricostruzione dei valori su cui si fonda l'istituto imperiale.

13 Per un violento paradosso, in cui si riconosce la cifra del poema, lo scioglimento finale avviene nell'assenza degli dèi: Giove esce di scena prima del duello fratricida, per fuggirne l'orrore; l'undicesimo libro porta a compimento il suo piano punitivo, ma il piano culmina in un nefas che neppure Giove vuole vedere (la regìa è lasciata alle Furie); nel libro successivo, quasi senza preannuncio divino, Teseo si sostituisce al padre degli dèi e prende su di sé il compito della ricostruzione, come un eroe epico autosufficiente ${ }^{20}$, in nome di valori collettivamente riconosciuti.

La rottura dell'impianto provvidenziale che unificava l'Eneide non potrebbe essere più evidente. Nella Tebaide quello di Giove è un disegno distruttivo, che appare privo di una finalità positiva chiaramente indicata, e coincide di fatto con l'azione delle Furie infernali; la guerra che lo realizza è una guerra sbagliata, il duello che lo sigla è un culmine di empietà. Fino all'undicesimo libro, il poema è in gran parte un'epica negativa, senza vincitori, priva di telos: un'epica del nefas, che sovverte la funzione celebrativa del genere e, rovesciando Virgilio, si modella sull'epica di Lucano e sulla tragedia di Seneca ${ }^{21}$.

15 Ma il dodicesimo libro - la seconda metà del dodicesimo - inverte la rotta: un calcolato effetto di sorpresa stacca il finale dal resto del poema e conduce con rapidità il lettore allo scioglimento (per quanto provvisorio) della vicenda. Il re di Atene, città ideale in cui si venera la Clemenza, guida una spedizione per recuperare i corpi insepolti degli Argivi, uccide il nuovo tiranno di Tebe, Creonte, e viene accolto in città come un liberatore. Paradossalmente, gli dèi della tradizione epica devono tramontare perché quest'epica nuova possa trovare infine una via d'uscita dalla crisi: lo screditato apparato divino, che per undici libri ha prodotto distruzione, lascia ora il posto all'azione umana ispirata dalla clementia, la sola capace di riaffermare valori etico- 
politici e di trasformare infine un epos in crisi in un'epica - così parrebbe - di vittoria e di trionfo.

Una riconversione estrema, che trova tuttavia il suo senso solo nell'unione e nella tensione con ciò che precede. È proprio nella dissonanza tra le due parti dell'epos, così vistosamente sbilanciate, che si coglie il senso complessivo della Tebaide, della sua forma narrativa e del suo discorso politico. Si è spezzato il disegno unitario che, nell' Eneide, faceva coincidere narrazione epica e provvidenza: se Virgilio celebrava il mito di fondazione del potere imperiale, a un secolo di distanza il mito narrato da Stazio rappresenta, di quel potere, la degenerazione e la (auspicata) rifondazione. Dalla disarmonia di una composizione scissa ed asimmetrica si sprigiona così il senso di un'architettura poetica innovativa e di una faticosa elaborazione ideologica: uno sforzo di ricostruzione che non cancella la coscienza di una crisi, e che esprime una perdurante inquietudine, letteraria e politica a un tempo.

Letture unilaterali, che schiacciano anche il finale sulla visione negativa del corpo dell'opera, o, al contrario, pretendono che la conclusione riscatti tutto l'insieme in un finalismo epico positivo ${ }^{22}$, non rendono ragione di questa inquieta complessità. La chiusa del racconto è insieme una risoluzione epica positiva e l'ultimo atto di una tragedia - e non è un caso che la via d'uscita dalla tragedia tebana (la tragedia delle Fenicie cui il racconto di Stazio si è fin qui sovrapposto) fosse appunto materia di un'altra tragedia, ancora una volta essenziale a comprendere quest'ultimo tratto del poema: le Supplici di Euripide.

Esemplarità e pessimismo convivono, dunque, in questa chiusa: il contrasto con ciò che precede non potrebbe essere più netto, la continuità non potrebbe essere più profonda. Come un racconto esemplare, io credo, la Tebaide ha infine un eroe positivo e un ideale da indicare, contrappone a una spedizione maledetta una guerra giusta, e a un tiranno crudele un sovrano guidato dalla clementia; ma la versione ideale del potere assoluto incarnata da Teseo non fa che riparare, senza poterli riscattare, i danni che la degenerazione di quello stesso potere ha prodotto fin qui nel poema; e neppure una guerra rapida e legittima può restituire all'epica una rinnovata integrità, dopo tanti libri di devastanti impia bella. La Tebaide è un poema di contrasti netti e di opposizioni didascaliche, ma anche di compresenze tragiche e di paradossale coincidenza degli opposti: nel finale il trionfo non si distingue dal lutto, e alla vittoria segue il lamento funebre.

Forma epica e discorso politico si corrispondono nell'opera, per il contrasto interno che divide l'una e l'altro in due componenti antitetiche; la proposta ideologica di Stazio nasce dall'esperienza del dispotismo e ne porta i segni: il finale si regge in equilibrio sull'abisso del poema. Condanna della tirannide ed esaltazione della sovranità clemente sono due aspetti complementari, e in tensione fra loro, di uno stesso discorso sul potere imperiale e forse, indirettamente, rivolto al potere. Nello spazio sospeso del mito, la Tebaide pone con forza questioni che riguardano il presente, le riassume in una storia di rovina e di ripresa, le condensa in exempla negativi e positivi; ma, escluso ogni riferimento diretto e univoco alla realtà contemporanea, nei confronti dei detentori attuali del potere si mantiene equidistante (o in voluta ambiguità) fra elogio e ammonimento, fra celebrazione ed esortazione, forse addirittura fra denuncia e deterrente. In nessun punto del poema il senso del rapporto fra mito e storia è mai reso esplicito, se non in termini universali, sovratemporali. Il racconto mitico può apparire in accordo con la rappresentazione ufficiale del passato recente, perché si lascia 
sovrapporre, per analogia, alla sequenza orientata di tirannide neroniana, guerra civile, restaurazione flavia; ma nulla nel testo esclude un fascio di significati più complesso, che coinvolge questioni delicate come la successione e l'odio tra fratelli.

Tutto, anzi, fa pensare che i due poli opposti della narrazione siano concepiti come entrambi pertinenti a un discorso sul presente e al discorso sul potere assoluto in generale; clementia e inclementia regum vengono presentati qui alla riflessione come due aspetti sempre presenti in potenza nell'istituto del potere monarchico: due immagini da offrire ogni volta come specchio ai nuovi potenti, per esortare elogiando, per esorcizzare denunciando. L'autore epico non prende esplicitamente posizione, lascia piuttosto ai lettori il compito di misurare la distanza tra mito e realtà storica, e al destinatario imperiale la responsabilità di identificarsi con l'uno o l'altro polo della narrazione. Non a caso, non c'è qui l'immagine di una chiusura della storia, il senso di un passato superato e che non può tornare: la linearità della teleologia virgiliana ha lasciato il posto alla circolarità, alla coazione a ripetere e alla ricorsività del male, al ciclo ricorrente di violenza che è il marchio dei miti tebani (e che fa intravedere, oltre la chiusa del poema, la vendetta degli Epigoni).

21 C'è una punta polemica, nella descrizione dell'ara Clementiae, che non deve sfuggire: unde procul starent iraeque minaeque / regnaque, "da cui stessero lontane le ire e le minacce dei regni" (12, 504-5); con un gesto marcato di ammonimento e di denuncia, la clemenza viene contrapposta alla violenza del potere, del potere dispotico, il "regno" che fa tutt'uno con l'ira e le minacce, gli strumenti del tiranno. La clemenza è una difesa dalle degenerazioni del potere assoluto, lo stesso potere di cui rappresenta la versione ideale. Questo corto circuito rende evidente il nodo del problema: il potere di uno solo ha in sé, e in sé solo, la potenzialità di una realizzazione ideale e il pericolo di una degenerazione rovinosa. Lo stesso brano che celebra indirettamente la virtù imperiale, indirettamente accusa i guasti dell'impero: la tragedia dell'involuzione tirannica esemplificata fin qui dal racconto epico.

La riflessione critica di Stazio accosta dunque al pessimismo dell'analisi un tentativo di proposta positiva, un limitato ottimismo costruttivo. La clementia è il centro di un discorso etico e politico che appare in sintonia col discorso ufficiale del potere, ma che lo muta alla radice e lo rinnova dall'interno attraverso il linguaggio mitico e poetico ${ }^{23}$. Con la sua insistenza, il testo suggerisce che si tratta di un valore fragile e minacciato, che va ogni volta riaffermato e raccomandato a chi regna, che va, soprattutto, ridefinito e approfondito nelle sue basi concettuali: sfruttato dalla propaganda imperiale, realizzato episodicamente e ripetutamente violato nella pratica politica, screditato dall'abuso che gli imperatori ne hanno fatto (o addirittura scaduto a maschera del dispotismo), il valore-cardine dell'ideologia politica romana deve essere rifondato; è un rinnovamento dell'ideale imperiale quello che il poeta epico propone, indicando un ritorno alle origini e costruendo per la clementia un mito di fondazione ${ }^{24}$.

Il tentativo di Stazio nel finale della Tebaide assomiglia a quello di Seneca nel De clementia: e il finale epico contrasta con la tragedia del potere rappresentata dal poema, come l'utopia del De clementia si contrappone alla visione del potere inscenata nelle tragedie senecane.

24 È tenendo presenti queste considerazioni (in cui ho anticipato in parte i risultati dell'analisi) che vorrei qui esaminare in dettaglio qualche aspetto del ruolo di Teseo e della clementia nella chiusa della Tebaide, cercando di ricostruire il rapporto organico che lega l'uno all'altra, da più parti e in vario modo messo in discussione ${ }^{25}$. Occorre, 
credo, tornare a considerare i presupposti culturali e i precedenti poetici su cui Stazio lavora, i procedimenti artistici della sua rielaborazione, e la proposta ideologica che da questa costruzione viene fatta emergere.

Un'assenza si nota, anche negli studi più recenti. La critica staziana tende a sottovalutare l'importanza di presupposti culturali e letterari greci nell'elaborazione del poema, in particolare il modello delle Supplici di Euripide ${ }^{26}$ : e così non solo oscura un elemento cruciale per l'analisi del testo, ma non si accorge di ripercorrere linee già tracciate dalla critica euripidea, di riproporne problemi e divisioni. Si continua, insomma, a parlare di Teseo e della sua relazione con la clementia come se questo tema, con altri termini e modalità diverse, non fosse già stato messo in forma nel dramma di Euripide; si discute, qualche volta, di questo Teseo come se venisse dal nulla (o, tutt'al più, dal carme 64 di Catullo), e non dalla ricca tradizione mitico-letteraria e ideologicopolitica raccolta intorno all'eroe nazionale ateniese; si distingue la sua funzione da quella dell'ara Clementiae come se la figura del re mitico non fosse stabilmente chiamata a rappresentare, al più alto grado, l'ideale che rende grande e ammirata nei secoli la sua città, Atene: appunto la $\varphi \imath \lambda \alpha v \theta \rho \omega \pi i ́ \alpha$, il soccorso dei supplici, la difesa dei deboli e degli oppressi, che non esclude l'uso della forza e, anzi, prevede l'intervento in armi da parte di una potenza imperialistica - il precedente diretto, insomma, di quel più vasto concetto di clementia che è qui definito e rappresentato.

Un'altra tendenza è spesso operante: si trascura, io credo, di esaminare il testo di Stazio nella peculiarità dei suoi intenti artistici, delle sue forme poetiche e delle sue strategie comunicative, mentre si applicano, in modo piuttosto indiscriminato, metodi di analisi testuale miranti a una decostruzione del personaggio, con atteggiamenti e risultati talvolta scopertamente pregiudiziali. Si tende cioè a sovrastimare aspetti problematici di Teseo che sarebbero suggeriti (sotto la superficie testuale) da allusioni e risvolti ambigui, mentre si sottovaluta l'esplicitezza della voce epica che ne accompagna e giustifica l'agire, e si scredita l'impostazione fin troppo scopertamente didascalica della narrazione. È un modo di procedere noto, soprattutto, alla critica virgiliana: si svaluta ciò che nel racconto è dichiarato, esibito, programmaticamente commentato, e si lavora su tratti marginali, pieghe nascoste, sottintesi o ambiguità, alla ricerca di 'altre voci', polemiche e sovversive, in contrasto con la voce epica 'ufficiale'.

Un procedimento che risulta, per il testo di Stazio, forse ancora più rischioso che per quello di Virgilio: tale è, nella Tebaide, l'impostazione palesemente esemplare del racconto, l'invadenza della voce autoriale a commento della vicenda, la pervasività dell'atteggiamento sentenzioso e didascalico. Un testo pur denso di implicazioni problematiche, ricco di tensioni ossimoriche, sfaccettato e complesso, permeato da un pessimismo di fondo e da una visione intimamente contrastata, si regge tuttavia su un'impalcatura principale, narrativa e ideologica, evidente ed esibita: un racconto paradigmatico, costruito a contrasto, che proprio in chiusa ritaglia la figura del buon re come rovescio del tiranno, e oppone l'uno all'altro come modelli antitetici. Ingigantire le 'ombre' di Teseo, che il testo di Stazio non nasconde, ma lascia sullo sfondo e segnala alla memoria del lettore, è un'operazione che inverte i rapporti di forza e la gerarchia dei significati istituita dalla costruzione poetica. Così come ridurre, fin quasi ad annullarle, le differenze fra Teseo e Creonte, o fra Teseo ed Edipo, vuol dire smontare un sistema di opposizioni e fare del testo un tutto indistinto (una notte in cui tutti i sovrani sono neri), privarlo insomma delle distinzioni essenziali alla sua leggibilità e capacità di significazione ${ }^{27}$. 

altrove ${ }^{29}$. La distanza è enorme, ma il rapporto è vitale, e investe la geometria profonda dei significati: Atene contrapposta a Tebe, come il mondo dei valori umani e politici alla violenza del potere (il grande tema della tragedia attica individuato da Froma Zeitlin) ${ }^{30}$; la guerra come dura necessità e come prova suprema per affermare la giustizia; il lutto femminile che perdura, senza riscatto. La scelta della variante mitica guerresca canonizzata da Euripide (contro la versione pacifista degli Eleusini di Eschilo, con la soluzione diplomatica della crisi) rivela già da sé l'adesione di Stazio alla sostanza tragica dell'invenzione euripidea: una guerra giusta e legittima, che scioglie un nodo tragico ma non ne risolve un altro, rendendo infine possibile il tributo del lutto ai caduti di una guerra ingiusta ed empia, che non avrebbe mai dovuto essere combattuta. Mettendo le Supplici in continuazione diretta con le Fenicie (il loro antefatto mitico) Stazio esalta gli effetti di contrasto, tra spedizione riparatrice e spedizione maledetta dei Sette, e insieme ne crea di nuovi: di fronte allo slancio eroico degli Ateniesi, il quadro dei Tebani stanchi di guerra, costretti dal nuovo tiranno a riprendere le armi appena posate, ancora insanguinate e a pezzi, conferisce al dramma della guerra rinnovata una nuova profondità ${ }^{31}$.

Questa compresenza tragica è essenziale, nel finale di un'epica che sulla tragedia, euripidea e senecana soprattutto, è in larga parte modellata. È sintomatico che, nell'affrontare questa complessità, la critica staziana riproduca inconsapevolmente discussioni e divisioni della critica euripidea. La spedizione ateniese è giustificata dal testo, ma in lettori e critici sazi di guerra (e di imperialismi) si fa strada l'idea che Stazio, rappresentando il dramma di uno scontro rinnovato, voglia indirettamente screditare alla radice la decisione del ricorso alle armi $^{32}$. Per ribattere a questa posizione si potrebbero usare le parole con cui Paduano, in uno studio sulle Supplici non recente ma ancora importante, reagiva a interpretazioni negative e ironiche della tragedia e del suo protagonista ${ }^{33}$ : “Teseo, aiutando gli Argivi... compie... un'opera di 
giustizia fondata su un imperativo etico universale e immediato... Che poi per la difesa di questo o di simili principi, Euripide ritenga giusto e necessario il pur rovinoso mezzo bellico, mi pare altrettanto indubbio... sono incontrovertibili ugualmente l'ingiustizia dei Tebani e il dovere di Teseo di opporsi ad essa in nome dell'etica ellenica... la guerra si impone come un portato necessario dei fatti e degli antefatti...". In contrasto con critici demolitori come Fitton, è appunto il nodo tragico della guerra in funzione di giustizia che viene sottolineato: "Che l'opera di giustizia debba essere dolorosa e spesso inquietamente incerta, non è una novità da spiegare, è uno dei temi fondamentali del teatro antico. Si può vedervi una sorta di pensosa e tremenda ironia tragica, se si vuole, ma non certo quella satira di Atene e della sua missione umana e civile che vorrebbero vedervi, particolarizzando e banalizzando il motivo, il Blaickock e il Greenwood, oltre il già citato Fitton" (corsivi miei). E ciò che vale per il nodo della guerra vale in certa misura, come vedremo, per il giudizio sul personaggio di Teseo: "si può lungamente discutere sull'eticità personale di Teseo, non però sul fatto che l'azione da lui compiuta sia indiscutibilmente etica, che la giustizia combatta al suo fianco...".

Due opere distanti, dunque, ma similmente contrastate tra l'esaltazione di un ideale politico e una concezione profondamente pessimistica: si ripropone in forme nuove, nella Tebaide, la tensione delle Supplici fra patriottismo ateniese e discorso antibellicista, tra nostalgia dell'ideale pericleo e messaggio pacifista sull'orrore di ogni guerra ("anche quella che gli Ateniesi combattevano contro gli Spartani"), una tensione che Di Benedetto ha ben illustrato ${ }^{34}$; l'equilibrio difficile, insomma, di un dramma concluso da una vittoria, ma "dominato dal principio alla fine dalla rappresentazione del lutto" 35 .

Definite nell'hypothesis, e forse da Aristofane di Bisanzio, "Encomio degli Ateniesi", le Supplici sono, almeno in parte, una tragedia patriottica: "Il re degli Ateniesi... viene presentato nell'atto di difendere una giusta norma panellenica, sua madre viene raffigurata come piena di comprensione per le infelici donne venute da Argo, la guerra che l'esercito ateniese fa ai Tebani si conclude con la sua vittoria, e più volte nella tragedia si fanno le lodi di Atene, come città libera e pronta a soccorrere i deboli e gli infelici"; tuttavia, è difficile non riconoscere che "un giudizio del genere coglie solo la superficie della tragedia", che "l'accento batte altrove, e proprio sulla rappresentazione della crisi dei valori "patriottici" ${ }^{36}$. È questa discrepanza fra idealizzazione e pessismismo, in un racconto mitico denso di riflessione politica, che ritroviamo in forma nuova nell'epos staziano.

Le Supplici sono un dramma eminentemente politico, ed eminentemente politico è il discorso di Stazio nella chiusa della Tebaide: della tragedia euripidea il poeta flavio dà una reinterpretazione in chiave attuale. I punti-cardine del suo discorso - Teseo, la Clementia e la punizione dei tiranni - segnano la distanza da Euripide: il restauro di Teseo come personaggio mitologico e come sovrano ideale (anziché figura civica e capo democratico); il suo rapporto col valore imperiale della clementia; la sua azione come tirannicida, sono le innovazioni decisive. Eppure proprio alle Supplici, come matrice generativa di uno sviluppo nuovo, andrà riconosciuto il giusto rilievo nell'analisi del finale e del suo significato politico.

Il dramma euripideo esalta il sistema democratico in opposizione alla tirannide, anche se lascia spazio a critiche della demagogia attuale e fa trapelare sfiducia nella realtà politica contemporanea ${ }^{37}$. Manipolando il mito di Teseo in modo fino ad allora inedito, Euripide attribuisce al mitico re fondatore di Atene il merito di fondatore della 
democrazia, e di rappresentante di una sua versione dirigista e periclea, inattuale e idealizzata ${ }^{38}$. Il contrasto fra Teseo e l'araldo di Tebe mette in scena, nel cuore del dramma, un confronto fra democrazia e tirannide: un dibattito costituzionale su diverse forme di governo, ove la tirannide fornisce un termine di contrasto contro cui definire l'identità ateniese, e insieme fa risaltare per opposizione i difetti del governo democratico (è il ruolo che svolge nel discorso politico della democrazia un sistema ormai inattuale nel $\mathrm{V}$ secolo) ${ }^{39}$. Con il suo anacronismo, che avrà fortuna, Euripide fa di Teseo un padre nobile della democrazia ${ }^{40}$; l'elogio del sistema democratico si affianca così alle lodi proprie già dell'Atene mitica: ospitalità, protezione dei supplici, soccorso dei deboli e degli oppressi - le qualità rappresentate appunto nella tragedia. È in virtù del sistema democratico, mostra Euripide, che Atene è in grado di far rispettare leggi panelleniche e valori universali, come il diritto alla sepoltura rivendicato qui dagli Argivi.

Ma torniamo alla Tebaide. Stazio traduce Euripide in termini attuali, sposta il discorso dal piano del dibattito costituzionale a quello della discussione etico-politica: non più un confronto tra diverse forme di governo, ma una riflessione sul buono o cattivo uso della forma monarchica; è l'ambito della riflessione politica proprio della Roma imperiale, e di tradizione ellenistica. Il contrasto fra Atene e Tebe diventa qui la contrapposizione fra re e tiranno: un confronto personalizzato, e condotto in forme narrative, fra Teseo e Creonte ${ }^{41}$. Teseo è qui di nuovo il sovrano ideale che incarna $\mathrm{i}$ valori di umanità di Atene: così come era già tornato ad essere, dopo la forzatura di Euripide, nell'Edipo a Colono di Sofocle. Ciò che è violato, e deve essere riaffermato, non sono più norme panelleniche, ma le leggi universali e l'ordine cosmico (terrarum leges et mundi foedera, 12, 642) garantiti dalla monarchia ideale: l'intervento ateniese ristabilisce la coesione dell'universo su cui si modella, e in cui si rispecchia, l'ordine politico.

37 C'è un'altra novità; oltre che la città di Teseo, Atene è la città dell'ara Clementiae, l'altare sacro agli sventurati dove si rifugiano le donne argive ${ }^{42}$. Spostata l'azione da Eleusi ad Atene, il tempio di Demetra viene sostituito da un luogo simbolico, sintesi audace di valori greci e romani. Stazio trasforma il $\beta \omega \mu$ ò $\dot{c} \lambda \varepsilon ́ o v$, l'Altare della Pietà testimoniato nell'agorà ateniese, in monumento $\mathrm{a}$ un valore-cardine dell'ideologia imperiale romana, la clemenza, e ne fa il cuore del poema. È qui che Teseo, in trionfo come un capo romano per la vittoria contro le Amazzoni, ascolta benevolo, dall'alto del carro, la richiesta di Evadne, e si impegna all'azione; è qui che promette guerra contro il tiranno Creonte, la cui condotta è stata bollata poco prima come inclementia regum $(11,684)$.

Con l'associare Teseo alla clementia, il discorso politico delle Supplici è così aggiornato ai tempi: l'orizzonte politico è ora quello imperiale; il dibattito corrente è la distinzione fra buon re e tiranno; il discrimine fra sovrano e tiranno si riassume in una virtù: è un esercizio del potere assoluto che trova il suo limite nella clemenza - siamo, come si è detto, sulla linea del De clementia di Seneca.

\section{Teseo e Creonte: re e tiranno, 'clementia' e 'inclementia regum'}

Nel disegno del poema, il ritratto di Teseo come re clemente acquista senso dalla contrapposizione con la inclementia regum di cui è paradigma Creonte. Al momento della successione al trono di Tebe, nel libro undicesimo, il narratore epico commentava la 
trasmissione della tirannia nella lignée tebana e rifletteva sulla seduzione del male insita nel potere: [sc.Creon] scandit fatale tyrannis / flebilis Aoniae solium. pro blanda potestas / et sceptri malesuadus amor! numquamne priorum / haerebunt documenta novis?iuvat ecce nefasto / stare loco regimenque manu tractare cruentum! (11, 654-8). Si noti l'uso di documenta ("ammonimenti che vengono dall'esempio"), un termine importante per la poetica della Tebaide ${ }^{43}$ : questo nuovo intervento della voce autoriale mostra la vanità del monito rivolto ai reges ottanta versi prima, a commento del duello fratricida fra Eteocle e Polinice (soli memorent haec proelia reges, 11, 579). E ancora: primum adeo saevis imbutus moribus aulae / indicium specimenque sui iubet igne supremo / arceri Danaos, nudoque sub axe relinqui / infelix bellum et tristes sine sedibus umbras (11, 661-4) $)^{44}$. Il divieto di sepoltura è nel racconto di Stazio l'ennesima manifestazione della tirannia, cui si contrappone infine la clemenza di Teseo (è interessante che la formula usata per registrare il primo delitto del nuovo tiranno sia parallela a quelle che Tacito riserverà in qualche caso alla successione imperiale: ann. 1, 6, 1 primum facinus novi principatus fuit Postumi Agrippae caedes...; 13, 1, 1 prima novo principatu mors Iunii Silani proconsulis Asiae ignaro Nerone per dolum Agrippinae paratur... $)^{45}$.

Comunque si valuti il personaggio di Teseo, va riconosciuto che esso svolge innanzi tutto una fondamentale funzione contrastiva. La schematizzazione del racconto rispetto alle Supplici è evidente: Creonte è il paradigma del tiranno, ed è un tiranno recidivo, patologico, parossistico. Il divieto di sepoltura è qui, a differenza che in Euripide, ribadito, riassaporato e rincarato più volte, con tratti di sadismo degni dell'Atreo senecano: così nel lamento del re per la morte del figlio Meneceo, 12, 94-103 'saevum agedum immitemque vocent si funera Lernae / tecum ardere veto; longos utinam addere sensus / corporibus caeloque animas Ereboque nocentes / pellere fas, ipsumque feras, ipsum unca volucrum / ora sequi atque artus regum monstrare nefandos! / ei mihi, quod positos humus alma diesque resolvet! / quare iterum repetens iterumque edico: suprema / ne quis ope et flammis ausit iuvisse Pelasgos; / aut nece facta luet numeroque explebit adempta / corpora; per superos magnumque Menoecea iuro'; così, indirettamente, nell'avvertimento di Ornito alle donne Argive: 12, 149-59 'quo, miserae, quo fertis iter? funusne peremptis / speratis cineremque viris? stat pervigil illic / umbrarum custos inhumataque corpora regi / adnumerat. nusquam lacrimae, procul usque fugati / accessus hominum: solis avibusque ferisque / ire licet. vestrisne Creon dabit aequus honorem / luctibus? inmites citius Busiridos aras / Odrysiique famem stabuli Siculosque licebit / exorare deos; rapiet fortasse precantes, / si mens nota mihi, nec coniugialia supra / funera sed caris longe mactabit ab umbris'; così nella risposta ostinata e provocatoria dello stesso Creonte all'araldo di Teseo, che si contrappone (con variazione significativa) al silenzio del re di Tebe nelle Supplici: 12, 689-92 'parvane prostratis' inquit 'documenta Mycenis / sanximus? en iterum qui moenia nostra lacessant. / accipimus, veniant; sed ne post bella querantur: / lex eadem victis ${ }^{46}$.

41 La caratterizzazione di Creonte - vale la pena di segnalarlo, come un dettaglio rivelatore - riproduce, persino nella forma dell'espressione, tratti tirannici del Cesare lucaneo. L'ossessione numerica del sovrano di Tebe per i corpi degli Argivi, già accennata in precedenza $(12,102$ numero, 152 adnumerat), culmina nella descrizione della battaglia finale. A una notazione neutra di Euripide, sulla posizione dello schieramento tebano rispetto ai cadaveri oggetto della contesa (Suppl. 664-5 Kó $\delta \mu o v ~ \delta \check{\varepsilon}$

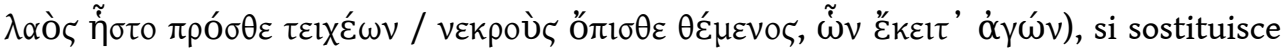
in Stazio un enfatico commento del narratore: 12, 715-20 hunc saltem miseris ductor Thebanus honorem / largitur Danais, quod non super ipsa iacentum / corpora belligeras acies 
Martemque secundum / miscuit, aut lacera ne quid de strage nefandus / perderet, eligitur saevos potura cruores / terra rudis. La preoccupazione del tiranno di "non perdere nulla" del mucchio di cadaveri nemici replica, anche nella forma dell'espressione, il compiacimento di Cesare e il suo desiderio di "non perdersi lo spettacolo" della strage dopo la battaglia di Farsalo, davanti ai corpi che coprono il campo: Luc. 7, 796-7 ac ne laeta furens scelerum spectacula perdat, / invidet igne rogi miseris ${ }^{47}$...

Se, per undici libri, la Tebaide si è modellata in gran parte sulla Pharsalia, come epica del nefas trascinata da una forza negativa, il dodicesimo libro rappresenta un superamento, o addirittura un rovesciamento di Lucano: qui il tiranno sta per essere sconfitto e ucciso, non è il vincitore ma il vinto. Il poema di Stazio ha una prospettiva imperiale compiuta; a chi vorrebbe allineare anche il finale al discorso contro l'impero e al sarcasmo verso la clementia Caesaris espressi da Lucano, si può indicare un altro, significativo rovesciamento del Bellum civile nella chiusa dell'epos. 'terrarum leges et mundi foedera mecum / defensura cohors' (12, 642-3): così Teseo esorta a un'impresa che ristabilisce, insieme a "norme" etiche comuni all'umanità (le "leggi" delle Supplici) ${ }^{48}$, anche l'ordine naturale che rispecchia l'ordine politico, il cosmos che corrisponde all' imperium - proprio quell'ordine cosmico che la Pharsalia dichiarava sconvolto senza rimedio, nel passaggio dalla repubblica all'impero. La iunctura foedera mundi, come altre analoghe, era impiegata da Lucano ad indicare la coesione fisica dell'universo messa a repentaglio dalla guerra civile: Luc. 1, 72-80 sic, cum compage soluta / saecula tot mundi suprema coegerit hora, / antiquum repetens iterum chaos [...] totaque discors / machina divolsi turbabit foedera mundi; 2, 1 ss. iamque irae patuere deum, manifestaque belli / signa dedit mundus, legesque et foedera rerum / praescia monstrifero vertit natura tumultu / indixitque nefas ${ }^{49}$. Vicino in questo a Seneca più che a Lucano, Stazio ripristina la visione della monarchia come sistema di governo conforme a natura, in accordo con la cosmologia stoica $^{50}$.

Se Creonte è un tiranno da manuale, la soluzione della guerra (è inevitabile) appare fin dall'inizio senza alternative. Così già nelle parole del reduce argivo, Ornito, in 12, 160-6 'quin... aut vos Cecropiam (prope namque et Thesea fama est / Thermodontiaco laetum remeare triumpho) / imploratis opem? bello cogendus et armis / in mores hominemque Creon' - la giustificazione dell'impresa ateniese è preparata di lontano. Anche l'immediatezza della decisione di Teseo e la rapidità dell'intervento in armi, altra deviazione vistosa dalle Supplici, è frutto di un'accorta strategia testuale. La condensazione del modello è dichiarata anticipatamente, con un segnale allusivo che agisce per antifrasi, nelle parole di Argia in 12, 210-2 'anne' ait ... 'expectem quaenam sententia lenti / Theseos, an bello proceres, an dexter haruspex / adnuat?': parole che rimandano al lento maturare della decisione di Teseo nelle Supplici, ma fanno risaltare, per contrasto, la prontezza della sua risposta qui nella Tebaide ${ }^{51}$. La traccia del modello è un'esca narrativa ingannevole, che esalta la novità della costruzione epica. All'impazienza di Argia si contrappone la fulmineità di Teseo nel reagire alla supplica di Evadne, con l'emanazione istantanea di un ultimatum: 12, 596-8 'nulla mora est; verte hunc adeo, fidissime Phegeu, / cornipedem, et Tyrias invectus protinus arces / aut Danais edice rogos aut proelia Thebis'. Di qui in poi saranno fitti nel racconto gli indicatori di velocità, a ritmare il raccogliersi spontaneo delle truppe, la marcia ininterrotta verso Tebe, lo scendere in campo di Teseo alle prime luci dell'alba ${ }^{52}$; e quasi un emblema del principio artistico che informa il finale è l'effetto immediato e miracoloso che la sola decisione ateniese produce a distanza su Tebe: 12, 609-10 necdum Atticus ire parabat / miles, et infelix expavit classica Dirce. 

sul testo tragico. La materia di buona parte delle Supplici è compressa in circa trecentocinquanta versi, con una selezione che riduce al minimo il numero dei personaggi, l'ampiezza dei dialoghi, la successione degli episodi, e conduce dritto alla conclusione - che qui è il tirannicidio. La tempestività di Teseo nell'epos si contrappone alla sua incertezza e riluttanza iniziale nel dramma: sulla scena l'evoluzione del personaggio avveniva, dopo il dialogo con Adrasto, attraverso il dibattito con la madre Etra; nella Tebaide, il maturare della risoluzione grazie al confronto dialettico lascia il posto ad un'adesione immediata alla causa delle Argive. Eliminata la discussione col re di Argo e con la madre, Stazio vi sostituisce la supplica, immediatamente efficace, di Evadne, e presenta così come un dato di partenza quello che era nel dramma il punto di arrivo e l'esito di un lento sviluppo: la disponibilità di Teseo, in nome del più ampio concetto di umanità rappresentato da Atene (e ricordatogli là da Etra), a soccorrere un popolo pur non esente da colpa, a ristabilire un diritto violato - l'universale diritto alla sepoltura - anche in difesa di chi si è reso responsabile di una guerra illegittima, "senza giustizia", intrapresa contro la volontà degli dei ${ }^{53}$. Il nodo problematico che nel dramma era sviscerato e superato attraverso il duplice contraddittorio non è ignorato qui, ma resta sottinteso e viene suggerito da Stazio con pochi, discreti segnali contenuti nella preghiera di Evadne. Il problema dell'errore degli Argivi, che Teseo nel dramma rimproverava ad Adrasto, è implicito qui nella scelta stessa della moglie di Capaneo (il più empio degli eroi) come portavoce delle Argive, ed è segnalato al lettore attraverso le sue stesse parole di persuasione: le rivendicazioni e proteste della donna eludono a stento la coscienza della colpa, e hanno l'effetto di evocarla di fronte a chi legge ${ }^{54}$; mentre il suo appello a un superiore senso di umanità, di universale comunanza tra gli esseri umani garantita dalla natura, prevale senza dubbio su ogni altra considerazione $^{55}$. Ancora una volta, significati e valori di un dramma che è stato ripensato e ridisegnato radicalmente sono riassorbiti e rifusi da Stazio nella nuova costruzione.

La risposta di Teseo a Evadne è già un confronto diretto con Creonte, apostrofato in absentia e messo di fronte a un aut aut: 12, 588-98 rubuit Neptunius heros / permotus lacrimis; iusta mox concitus ira / exclamat: 'quaenam ista novos induxit Erinys / regnorum mores? non haec ego pectora liqui / Graiorum abscedens, Scythiam Pontumque nivalem / cum peterem; novus unde furor? victumne putasti / Thesea, dire Creon? adsum, nec sanguine fessum / crede; sitit meritos etiamnum haec hasta cruores...'. In primo piano è lo sdegno di un (buon) re contro i novos... regnorum mores. L'estremizzazione dei contrasti si combina qui col gusto del paradosso - una combinazione cara a Stazio -: la 'sete di sangue', che è tratto tipico del tiranno ${ }^{56}$, diventa la 'sete di sangue colpevole, che merita punizione', attribuita a Teseo in veste di giustiziere. Pronunciando il proprio nome (a contatto con quello del nemico) il personaggio mitico si appropria del suo ruolo tradizionale di punitore dei malvagi, da lui stesso rivendicato nelle Supplici (e in seguito superato da

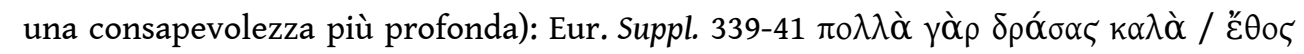

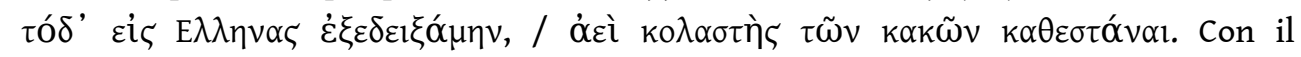
programmatico 'nec sanguine fessum / crede', pronunciato direttamente dal carro del trionfo, l'eroe civilizzatore e guerriero infaticabile, appena reduce dall'Amazzonomachia, si lancia senza esitazione nella nuova impresa contro la barbarie. 

supplica argiva (iusta mox concitus ira, 12, 589) si richiama la "giusta ira di guerra" che lo infiamma a Tebe nell'aria infetta dai cadaveri: dirisque vaporibus aegrum / aera pulverea penitus sub casside ducens / ingemit et iustas belli flammatur in iras $(12,712-4)^{58}$. La ripresa di un modello epico forte potrebbe bastare da sola a commentare questo passo; Teseo è animato contro Creonte dallo stesso sentimento che, nell'Eneide, spinge i sudditi di Mezenzio a combattere contro il tiranno: così in Verg. Aen. 10, 714 iustae quibus est Mezentius irae, e similmente già nelle parole di Evandro a Enea in 8, 494 s. 'ergo omnis furiis surrexit Etruria iustis, / regem ad supplicium praesenti Marte reposcunt [...] (498 ss.) retinet longaevos haruspex / fata canens: "o Maeoniae delecta iuventus, / flos veterum virtusque virum, quos iustus in hostem / fert dolor et merita accendit Mezentius ira..."... 59.

Quello che Stazio rappresenta qui è uno sdegno giustificato di fronte al male, come il legittimo sdegno ammesso dalla filosofia peripatetica contro cui Seneca polemizza nel De $\mathrm{ira}^{60}$. Tocchiamo qui un punto delicato. Anche sulla Tebaide, come sull'Eneide, si esercita talvolta una critica incline al fondamentalismo filosofico: dovrebbe essere evidente, credo, che non si può pretendere da un poema epico, per quanto costellato di temi, immagini e terminologia stoica, l'impegno filosofico e la coerenza dottrinale di un trattato senecano. Non si può, ma soprattutto non c'è ragione di farlo; c'è da chiedersi, piuttosto, che cosa sarebbe del genere epico se esso dovesse seguire la setta stoica nel rigore delle sue posizioni estreme, come il rifiuto categorico dell'ira e la negazione della sua utilità persino in guerra ${ }^{61}$ (Sen. de ira 1, 11, 8 Non est itaque utilis ne in proeliis quidem aut bellis ira) ${ }^{62}$. L'epica di Stazio va misurata con l'arte, e con la tradizione epica innanzi tutto, non col metro dell'etica stoica.

costruzione di questo finale va, semmai, inserita nel quadro di un dibattito più ampio e diffuso sul problema del rapporto tra ira e clementia, quale vediamo svilupparsi fra tarda repubblica e primo impero anche al di fuori delle scuole filosofiche, in contesti culturali e letterari diversi che fanno i conti con la profonda trasformazione politica in atto a Roma. Innanzi tutto si dovrebbe tenere in conto la possibile, diversa modulazione dello stesso discorso senecano fra teoria etica, da un lato, e precettistica filosofica ad uso del sovrano, dall'altro; lascia infatti frustrati una promessa non mantenuta nel $D e$ clementia, l'annuncio nel primo libro di una trattazione su "come ci si debba adirare coi nemici", non compiuta nel trattato così come lo possediamo: Sen. de clem. 1, 12, 3 Sed mox de Sulla, cum quaeremus quomodo hostibus irascendum sit, utique si in hostile nomen cives et ex eodem corpore abrupti transierint ${ }^{63}$.

Possiamo però constatare che, su questo punto, una differenza di tono fra contesti diversamente orientati esisteva già nelle opere ciceroniane. In sede teorica, trattando di clementia e magnanimitas nel De officiis, Cicerone respingeva in toto la concezione peripatetica dell'ira: Cic. off. 1, (25,) $88 \mathrm{Nec}$ vero audiendi qui graviter inimicis irascendum putabunt idque magnanimi et fortis viri esse censebunt; nihil enim laudabilius, nihil magno et praeclaro viro dignius placabilitate atque clementia. [...] 89 Prohibenda autem maxime est ira puniendo; numquam enim iratus qui accedet ad poenam mediocritatem illam tenebit quae est inter nimium et parum, quae placet Peripateticis, et recte placet, modo ne laudarent iracundiam et dicerent utiliter a natura datam. Illa vero omnibus in rebus repudianda est, optandumque ut ii qui praesunt rei publicae legum similes sint, quae ad puniendum non iracundia sed aequitate ducuntur; così come, trattando delle passioni nelle Tusculanae, rifiutava più specificamente, con esempi tratti dalla storia e dal mito, la tesi dell'utilità dell'ira in guerra $^{64}$. Parlando di fronte a Cesare vincitore, tuttavia, l'oratore lodava la clementia da 
lui dimostrata proprio in mezzo all'ira della vittoria: pro Marc. 9 At vero cum aliquid clementer, mansuete, iuste, moderate, sapienter factum, in iracundia praesertim, quae est inimica consilio, et in victoria, quae natura insolens et superba est, audimus aut legimus, quo studio incendimur, non modo in gestis rebus, sed etiam in fictis, ut eos saepe, quos numquam vidimus, diligamus!

Se nella discussione teorica ciceroniana la clementia è tenuta distinta dall'ira, nelle orazioni cesariane una possibile conciliazione tra i due atteggiamenti è di fatto riconosciuta ed ammessa, è anzi trasformata in motivo di lode e impiegata come strumento di elogio (e di pressione) nei confronti del dittatore. La grandezza di un capo non viene fatta consistere, qui, nel non provare ira di fronte a un nemico (ira e vittoria sono anzi presupposte come coincidenti), ma nel saperla tenere a freno, smettere a tempo, amministrare ad arte ${ }^{65}$ : pro Marc. 8 Animum vincere, iracundiam cohibere, victo temperare, adversarium nobilitate, ingenio, virtute praestantem non modo extollere iacentem, sed etiam amplificare eius pristinam dignitatem, haec qui faciat, non ego eum cum summis viris comparo, sed simillimum deo iudico; 17 Vidimus tuam victoriam, proeliorum exitu terminatam: gladium vagina vacuum in urbe non vidimus. Quos amisimus cives, eos vis Martis perculit, non ira victoriae, ut dubitare debeat nemo quin multos, si posset, C. Caesar ab inferis excitaret, quoniam ex eadem acie conservat quos potest. Alterius vero partis nihil amplius dico quam id quod omnes verebamur: nimis iracundam futuram fuisse victoriam (inoltre 15 ...cum pacis auctores conservandos statim censuerit, ceteris fuerit iratior). Cicerone elabora dunque nel discorso politico, in considerazione delle nuove esigenze imposte dalla prospettiva di un potere assoluto, un concetto da tempo fissato in formulazioni proverbiali: vincere l'ira, e se stesso, è per un vincitore la vittoria più difficile, e la più grande ${ }^{66}$.

Questa elaborazione di un nuovo discorso del potere, nata in età cesariana, che tenta di conciliare la clementia con l'ira, anche in funzione parenetica e a scopo strumentale, prosegue nella prima età imperiale e ha una tappa significativa nell'Ovidio dell'esilio. Le elegie dal Ponto ribadiscono ad ogni passo che la condanna del poeta è stata motivata dalla "giusta ira" di Augusto, ma ripetono ad ogni passo che la clementia dello stesso Augusto può ora intervenire a mitigare la pena ${ }^{67}$ : si veda, ad esempio, come il poeta parla del principe (e, indirettamente, al principe) in Pont. 3, 6, 7-10 quanta sit in media clementia Caesaris ira, / si nescis, ex me certior esse potes... 23-4 principe nec nostro deus est moderatior ullus: / Iustitia vires temperat ille suas; o ancora 2, 2, 19 meritam post Caesaris iram... 109 mite, sed iratum merito mihi / numen adora... 119-20 victa tamen vitio est huius clementia nostro, / venit et ad vires ira coacta suas. Mi piace citare, a questo proposito, uno studio importante di Francesca Lechi (pp. 126-7): “l'imperatore viene [...] presentato [...] come un giudice la cui naturale clementia si trova ad essere ostacolata e momentaneamente soppressa solo da un giusto moto di reazione di fronte a una mancanza di estrema gravità. Non c'è contraddizione fra l'esigenza di iustitia e lo sdegno di chi ricorre a misure severe, la sua ira, come Ovidio non si stanca di ribadire [...] L'opposizione ira/clemenza è attiva già nelle orazioni cesariane di Cicerone [...] tuttavia l'ambito in cui deve esplicarsi l'atto di indulgenza in quei casi è straordinario, extra leges, ed è un portato del rapporto vincitore/vinto [...] Con l'assestamento e il consolidamento del principato augusteo il problema del rapporto fra clementia e iustitia assume un'importanza nuova, e dei tentativi di risolverlo le ultime elegie di Ovidio conservano più di un riflesso"68. L'equilibrio tra iusta ira e clementia, cui l'imperatore è chiamato nell'irrogazione delle pene e nell'amministrazione della giustizia, non è 
diverso - sottolinea Ovidio - dall'equilibrio che egli ha sempre dimostrato nei confronti dei nemici vinti.

In questa fitta costellazione di testi ovidiani uno, soprattutto, mi pare importante per la chiusa epica di Stazio: è il passo di Tristia 2 che esalta appunto la clementia di Augusto in guerra come modello per la sua condotta in pace. Per l'imperatore, sottolinea Ovidio, lo stesso giorno che mette fine alla guerra mette fine anche all' "ira di guerra", belli iram proprio il nesso che Stazio riferisce a Teseo in Theb. 12, 714 iustas belli... iras ${ }^{69}$. Così, il trionfo diventa addirittura una festa comune di vincitori e vinti, tra la concordia e la gioia collettiva che tende ad annullare la distinzione fra le parti: trist. 2, 43-50 tu veniam parti superatae saepe dedisti, / non concessurus quam tibi victor erat. / divitiis etiam multos et honoribus auctos / vidi, qui tulerant in caput arma tuum; / quaeque dies bellum, belli tibi sustulit iram, / parsque simul templis utraque dona tulit; / utque tuus gaudet miles, quod vicerit hostem, / sic victum cur se gaudeat, hostis habet. Il quadro ovidiano, iperbolico e paradossale, della gioia del trionfo condivisa dagli sconfitti è forse quanto di più vicino al finale della Tebaide si possa indicare; qui la guerra si trasforma in pace nell'istante stesso in cui il tiranno è ucciso, e, mentre Teseo viene accolto come un ospite in città e nelle case, le donne di Tebe manifestano la loro gioia - una gioia illustrata da Stazio con l'immagine del Gange soggiogato ed ebbro che accetta ed approva i riti di Bacco -: Theb. 12, 782-8 accedunt utrimque pio vexilla tumultu / permiscentque manus; medio iam foedera bello, / iamque hospes Theseus; orant succedere muris / dignarique domos. nec tecta hostilia victor / aspernatus init; gaudent matresque nurusque / Ogygiae, qualis thyrso bellante subactus / mollia laudabat iam marcidus orgia Ganges. Se è il trionfo di Augusto rappresentato sullo scudo di Enea, come è stato notato, a fornire il modello all'immagine del fiume sottomesso (Verg. Aen. 8, 726 Euphrates ibat iam mollior undis; Stazio disloca mollior in mollia... orgia e lo rincara con marcidus, mutando l'ammorbidirsi dell'ostilità in ebbrezza dionisiaca) ${ }^{70}$, la gioia esaltata delle donne vinte sembra invece espandere, in uno sviluppo narrativo iperbolico, l'osservazione di Ovidio nei Tristia. Stazio combina così in un unico gesto allusivo due testi poetici diversamente coinvolti nella costruzione dell'ideologia augustea, sul tema della vittoria, del trionfo e della clementia verso i vinti.

Rappresentando in Teseo l'equilibrio tra iusta ira e clementia (e il loro controllato avvicendarsi), il poeta flavio delinea un ideale imperiale che ripropone il modello di Augusto, nei termini in cui esso era stato definito, fra l'altro, dalla poesia ovidiana. Saper porre un termine all'ira, quando è venuto il tempo della clemenza: è questa la prerogativa di un buon sovrano ${ }^{71}$. Forse sempre in età flavia, l'autore dell'Octavia menziona il "dare un tempo all'ira" tra le manifestazioni di clemenza che hanno reso Augusto pari agli dei: [Sen.] Oct. 472 ss. sen. pulchrum eminere est inter inlustres viros, / consulere patriae, parcere afflictis, fera / caede abstinere, tempus atque irae dare, / orbi quietem, saeculo pacem suo. / haec summa virtus, petitur hac caelum via. / sic ille patriae primus Augustus parens /complexus astra est, colitur et templis deus. Secoli dopo, un poeta che ha in Stazio un modello importante attribuirà all'insegnamento della Clementia la capacità di Stilicone di smettere l'ira rapidamente: Claud. Stil. 2, 14-9 haec [sc. Clementia] docet ut [...] deponas ocius iram / quam moveas. Per tornare infine a Seneca, resta da ricordare che, nel negoziato tra filosofia stoica e potere imperiale tentato nel $D e$ clementia, il rifiuto dell'ira, assoluto e reciso in sede teorica, diventa invece (anche al di fuori del contesto bellico) un rifiuto qualificato, che perde necessariamente la sua rigidezza: 1, 5, 6 Non decet regem saeva nec inexorabilis ira ${ }^{72}$. 

propaganda augustea in funzione attuale, elabora il motivo del gioire degli sconfitti nella narrazione esemplare di un episodio storico di clemenza, questa volta accostato esplicitamente al comportamento in pace di Domiziano. Così, nei Punica, Silio esalta la clemenza di Marcello che, dopo la conquista di Siracusa, garantisce salva la vita agli abitanti e impedisce il saccheggio e la distruzione della città, tenendo a freno l'ira dei soldati ${ }^{73}$ : Sil. 14, 665-75 his tectis opibusque potitus / Ausonius ductor postquam sublimis ab alto / aggere despexit trepidam clangoribus urbem / inque suo positum nutu, stent moenia regum / an nullos oriens videat lux crastina muros, / ingemuit nimio iuris tantumque licere / horruit et propere revocata militis ira. / iussit stare domos indulgens templa vetustis / incolere atque habitare deis. sic parcere victis / pro praeda fuit, et sese contenta nec ullo / sanguine pollutis plausit Victoria pennis. Anche qui la clemenza del vincitore ha per effetto la gioia comune di vincitori e vinti: $14,679-80$ ast reliquum vulgus resoluta in gaudia mente / certarunt victi victoribus; e l'intento attualizzante diventa qui esplicito, nel riferimento al buon governo delle province in tempo di pace da parte di Domiziano, indicato con una perifrasi nell'elogio che chiude con enfasi il libro: 684-8 felices populi, si, quondam ut bella solebant, / nunc quoque inexhaustas pax nostra relinqueret urbes! / at, ni cura viri, qui nunc dedit otia mundo, / effrenum arceret populandi cuncta furorem, / nudassent avidae terrasque fretumque rapinae ${ }^{74}$. Altro e più grande modello di clemenza, nel finale dei Punica (per più tratti vicino a quello della Tebaide) Scipione, in più tratti affine a Teseo, vede aprirsi spontaneamente davanti a sé le rocche di Cartagine conquistata: Sil. 17, 618-9 hic finis bello. reserantur protinus arces / Ausonio iam sponte duci ${ }^{75}$.

Nel quadro di questa tradizione idealizzante, in cui la buona disposizione e la gioia dei vinti misura la clemenza dei vincitori, il finale di Stazio ha un rilievo eccezionale, e si distingue per l'istantaneità e l'intensità delle manifestazioni di gioia, e addirittura di affetto, che si scatenano al cessare delle armi (12, 782-8 cit.). L'affratellamento immediato tra le schiere sul campo di battaglia (pari solo a quello tra concittadini nell'episodio di Ilerda in Lucano), il tono quasi familiare degli inviti a Teseo, restituito così al suo ruolo tipico di hospes (tradizionale per l'eroe liberatore da mostri e consacrato dall'Ecale di Callimaco; iamque hospes Theseus 12, 784) ${ }^{76}$, la frenesia delle donne tebane, simmetrica a quella delle Argive, sono altrettanti elementi di una rappresentazione iperbolica, dall'intento esemplare, che conferisce alla clementia di Teseo vincitore un risalto in tutto straordinario.

Il confronto fra re e tiranno, inscenato nel contrasto fra Teseo e Creonte, è dunque elemento portante nel finale del poema. Il montaggio narrativo lo esalta, le notazioni d'autore lo sottolineano: fino al momento decisivo, in cui gli avversari si trovano infine l'uno di fronte all'altro, e la voce epica registra l'opposto atteggiamento dei due capi nei confronti del loro seguito: 12, 754-9 atque hunc [sc. Creonta] diversa bellorum in fronte maniplos / hortantem dictis frustraque extrema minantem / conspicit; abscedunt comites: sed Thesea iussi / linquebant fretique deis atque ipsius armis, / ille tenet revocatque suos; utque aequa notavit / hinc atque hinc odia, extrema se colligit ira... Se i compagni di Teseo lo lasciano solo per il duello, certi della vittoria, fidando in lui e nell'aiuto divino, Creonte tenta invano con le minacce (strumento del tiranno) di trattenere i suoi, che non nascondono ormai il proprio odio. La descrizione di Stazio traduce in forma narrativa la distinzione fra re e tiranno, in base all'affidabilità del loro seguito, tracciata da Seneca nel De clementia: Sen. de clem. 1, 13, 1 Placido tranquilloque regi fida sunt auxilia sua, ut quibus ad communem salutem utatur, gloriosusque miles (publicae enim securitati se dare 
operam videt) omnem laborem libens patitur ut parentis custos; at illum acerbum et sanguinarium necesse est graventur stipatores sui (si veda anche 1, 12, 3 Interim, hoc quod dicebam clementia efficit, ut magnum inter regem tyrannumque discrimen sit, uterque licet non minus armis valletur; sed alter arma habet quibus in munimentum pacis utitur, alter ut magno timore magna odia conpescat nec illas ipsas manus quibus se commisit securus aspicit). Circondato dall'odio dei suoi, ormai pari a quello dei nemici, Creonte appare come il tiranno dell'Eneide, Mezenzio, che in punto di morte, consapevole dell'odio della sua gente, prega Enea di assicurargli la sepoltura (insieme al figlio): Verg. Aen. 10, 903-6 'unum hoc, per si qua est victis venia hostibus, oro: / corpus humo patiare tegi. scio acerba meorum / circumstare odia: hunc, oro, defende furorem / et me consortem nati concede sepulcro'. 'Sepulcri' sarà l'ultima parola anche nell'apostrofe rivolta a Creonte da Teseo, che spontaneamente gli garantirà la sepoltura da lui negata ai nemici: 12, 780-1 'vade atra dature / supplicia, extremique tamen secure sepulcri'.

La costruzione narrativa a contrasto, che abbiamo osservato in alcuni snodi principali, è programmata per uno scopo preciso: il movimento finale del poema mira fin dall'inizio a un esito atteso, un'uccisione in duello che ha tutti i tratti di un tirannicidio.

\section{Teseo fra Grecia e Roma}

Su Teseo in Grecia e a Roma manca un lavoro complessivo; se il ruolo centrale dell'eroe ateniese nella cultura greca è stato oggetto di numerosi studi negli ultimi anni, la sua fortuna, relativamente modesta, nella letteratura e nella cultura latina resta invece piuttosto in ombra ${ }^{77}$. In mancanza di una visione d'insieme delle vicende del personaggio, chi esamina il Teseo della Tebaide spesso non va oltre il "perfido Teseo" del carme 64 di Catullo, o si limita a segnalare episodi meno nobili nel mito dell'eroe che Stazio implica allusivamente nel racconto. Questa restrizione della visuale produce, a mio parere, storture evidenti nella valutazione del personaggio; mentre si sopravvaluta il peso della tradizione catulliana - quasi che non fosse più possibile vedere Teseo con occhi diversi da quelli di Arianna nel famoso epillio -, si chiudono gli occhi davanti a rappresentazioni diverse, greche e latine, che hanno contato di più nella costruzione staziana dell'eroe.

La critica sovversiva e pessimistica fa leva su allusioni al passato e al futuro mitico che screditerebbero Teseo, mostrandolo in altri tempi traditore di donne e fonte di sventure per la sua famiglia, addirittura affine a Edipo nel causare la morte del padre e nel maledire il figlio. Nella biografia di un eroe dalla vita intensa, e dalla secolare esistenza letteraria, è normale che non tutti i capitoli siano allo stesso livello: anche a un autore che voglia trarne una selezione brillante, i lettori possono sempre opporre l'opacità delle parti tralasciate o messe in ombra, forzando magari le intenzioni del suo testo (è interessante che posizioni simili a quelle di alcuni studiosi di Stazio si ripropongano, in modo non del tutto indipendente, nella critica sulla Teseida di Boccaccio e sul Knight's Tale di Chaucer, dove è disegnata, anche sul modello staziano, una figura eroica non priva di trascorsi mitici ingombranti) ${ }^{78}$.

Nella carriera di Teseo, si sa, non mancano punti oscuri; Stazio li ha inclusi nel testo, con l'enciclopedismo che gli è proprio, esplicitamente o per via allusiva; ma va riconosciuto che $\mathrm{i}$ tratti problematici sono qui marginalizzati. Lasciamo da parte improbabili interpretazioni ostili di episodi mitici ideologicamente connotati, come l'Amazzonomachia, che sono per la cultura antica simbolo costante (ancora attivo a 
Roma) di vittoria della civiltà contro la barbarie ${ }^{79}$. Anche i tentativi di enfatizzare le affinità fra Teseo e Edipo, tuttavia, appaiono forzati: nel testo di Stazio persino la forma dell'espressione tende a scagionare l'eroe ateniese, nel verso che evoca il volo di Egeo dal capo Sunio e lo fa apparire, con effetto di illusione sintattica, frutto dell'inganno di

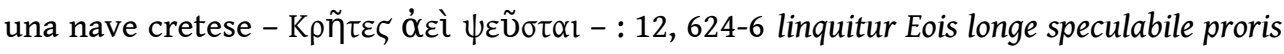
/ Sunion, unde vagi casurum in nomina ponti / Cresia decepit falso ratis Aegea velo ${ }^{80}$; mentre la gravidanza che trattiene Ippolita dal partecipare alla spedizione (12, 636-7 retinet iam certa tumentis / spes uteri) sembra davvero troppo poco per far pesare tutta intera su questo contesto la futura tragedia della maledizione di Ippolito da parte del padre ${ }^{81}$.

61 Quella cretese è certo l'impresa di Teseo più presente ai lettori di poesia romana. Il pallore catulliano di Arianna occupa in Stazio un verso defilato, letteralmente al margine, nella descrizione dello scudo su cui campeggia la vittoria sul Minotauro, 12, 674-6 veteres reminiscitur actus / ipse tuens sociumque gregem metuendaque quondam / limina et absumpto pallentem Cnosida filo ${ }^{82}$ : se è un segnale alla memoria del lettore - che ha ben in mente il destino della relicta - è un segnale della selezione che il poeta epico ha operato. Selezione e orientamento dei tratti: l'ekphrasis epico-eroica di Stazio rimette al centro della rappresentazione l'impresa contro il Minotauro (forse la più gloriosa di Teseo, prima che l'abbandono di Arianna la offuscasse) e relega ai margini, come un'appendice appena accennata, ciò che in Catullo costituiva il cuore dell'ekphrasis, e dell'epillio. Il verbo di memoria, reminiscitur, sollecita una memoria poetica potenzialmente imbarazzante, ma sottolinea, con un gesto provocatorio, la novità del contesto epico staziano, e suona quasi come una correzione dell'accusa di smemoratezza etica, immemor, che grava su Teseo in Catullo ${ }^{83}$.

62 Il racconto di Stazio assorbe in sé i tratti problematici, secondo una tendenza all'inclusività che caratterizza la Tebaide e la sua poetica onnicomprensiva, ma li neutralizza accuratamente nel disegno del testo, proprio come una secolare tradizione encomiastica aveva insegnato a fare. Se si vuole un termine di confronto, si può osservare il Teseo di Ovidio, non solo quello dell'Eroide di Arianna, ma anche quello del racconto epico delle Metamorfosi (per non parlare dei Fasti): la presenza di episodi imbarazzanti nel curriculum dell'eroe, spesso oscurati dalla tradizione eulogistica, non sfugge infatti all'ironia ovidiana. Il modo di procedere dei due poeti, di fronte alla multiforme tradizione sul personaggio, è sensibilmente diverso, se non addirittura opposto. Ovidio recupera l'aretalogia dell'eroe e il materiale tradizionale della Teseide (nata ad Atene nel VI secolo per contrapporre ad Ercole un eroe attico di pari valore) ${ }^{84}$, ma li fa smontare dalla voce di un'eroina abbandonata o li fa confliggere con tradizioni letterarie antagoniste, formulando accuse dirette ed esplicite. Si crea così una distanza ironica che (persino nel racconto epico) scredita i valori eroici rappresentati dal personaggio, li mette in discussione, li fa vedere in una prospettiva straniata, che è quella della tradizione elegiaco-catulliana. Così è, innanzi tutto, nell'epistola scritta a Nasso dalla relicta: che l'abbandono di Arianna costituisca un incidente nella carriera eroica di Teseo, spesso rimosso nella tradizione letteraria a lui più favorevole, è detto chiaramente dall'eroina stessa in her. 10, 125-30 ibis Cecropios portus, patriaque receptus, / cum steteris turbae celsus in ore tuae / et bene narraris letum taurique virique / sectaque per dubias saxea tecta vias, / me quoque narrato sola tellure relictam: / non ego sum titulis subripienda tuis ${ }^{85}$. Anche nelle Metamorfosi l'eroe non è però al riparo da critiche: qui è lo stesso narratore epico che, dopo aver fatto esaltare in un inno il catalogo delle imprese giovanili di Teseo in 7, 433-450, nel libro successivo completa a distanza il suo curriculum con una sintesi poco lusinghiera dell'impresa cretese, condita di un 
commento inequivocabile: met. 8, 172-6 ...utque ope virginea nullis iterata priorum / ianua difficilis filo est inventa relecto / protinus Aegides rapta Minoide Diam / vela dedit comitemque suam crudelis in illo / litore destituit. Desertae et multa querenti / amplexus et opem Liber tulit... ${ }^{86}$.

Nella Tebaide, Stazio lavora invece a restaurare la statura eroica di Teseo, ripulendo il personaggio da interpretazioni devianti rispetto al suo discorso epico, riportandolo a quell'immagine ideale che parte della tradizione (soprattutto) greca gli ha costruito addosso: e lo fa con la complicità del suo lettore, chiamato a partecipare a un processo di rieroicizzazione che rimpicciolisce e mette ai margini testi notissimi della letteratura latina. È lo stesso procedimento che Stazio adotta, ad esempio, nei confronti delle Eroidi ovidiane, là dove restaura con un gesto esibito la statura eroica di Giasone che l'Ipsipile elegiaca aveva compromesso, o dove fa sfiorare e rovesciare ad Argia il ruolo elegiaco di eroina abbandonata (una nuova Laodamia) che le sue parole e la sua situazione evocano - l'epica della Tebaide si apre ad accogliere le sollecitazioni di generi diversi, ma reagisce anche, con segnali evidenti, a difesa del codice eroico ${ }^{87}$.

Quando rimproverava a Teseo la mancata clementia nei suoi confronti, l'Arianna di Catullo - è un punto che andrebbe sottolineato - contestava un'illustre tradizione letteraria e lanciava un'accusa che doveva suonare paradossale: Cat. 64, 137-8 'tibi nulla fuit clementia praesto, / immite ut nostri vellet miserescere pectus?'. Ad essere messa in discussione, dal punto di vista di un'amante tradita, era, in quel passo, la reputazione di Teseo consolidata in una tradizione idealizzante: l'immagine di un sovrano mite, clemente, misericordioso, incarnazione dei valori ideali di Atene, costruita in secoli di cultura e di letteratura greca. È questa immagine che Stazio mira a ripristinare nel contesto epico, al di là delle forzature soggettive e strumentali della relicta di Catullo: rispetto alla tradizione elegiaco-catulliana, la sua è una vera e propria riabilitazione di Teseo.

Quello di Teseo è un mito complesso, ricco di aspetti che una lunga tradizione greca ha lavorato a interpretare e reinterpretare, di volta in volta esaltando o mettendo in ombra, riscattando e razionalizzando, secondo l'opportunità dei contesti storici e letterari. Soprattutto, nella cultura greca Teseo è un efficace simbolo politico, adottato in tempi diversi dai più vari discorsi del potere. È proprio questo il punto che la critica trascura: quella di Stazio è l'appropriazione di un simbolo, un simbolo potente e polivalente della cultura greca, che a Roma ha perso centralità culturale, ma che, almeno in letteratura, ha un precedente di riuso politico nella tragedia di Seneca: e io credo che sia per Stazio un precedente importante. Non viene mai citato, a proposito della Tebaide, il ruolo che Teseo svolge nell'Hercules furens (un'altra tragedia sulla tirannia tebana), come fiancheggiatore di Ercole nell'uccisione di Lico e come testimone e teorico della punizione dei tiranni da parte degli dèi e degli uomini, sulla terra e nell'aldilà.

La Tebaide termina con un tirannicidio: è una novità rispetto alle Supplici, che consacra come centrale il tema del potere e, allo stesso tempo, allinea la chiusa al finale dell' Eneide - il duello fra Enea e Turno. Teseo uccide Creonte e, mentre gli promette sepoltura, lo condanna alle pene dell'inferno; la sua apostrofe al tiranno è parallela, per forma ed autorevolezza, a quella che la voce delnarratore epico rivolgeva a Eteocle e Polinice nel libro precedente: Theb. 12, 771-3 'Argolici, quibus haec datur hostia, manes, / pandite Tartareum chaos ultricesque parate / Eumenidas, venit ecce Creon!', 779-81 'iamne dare extinctis iustos' ait 'hostibus ignes, / iam victos operire placet? vade atra dature / supplicia, 
extremique tamen secure sepulcri', da confrontare con 11, 574-5 ite, truces animae funestaque Tartara leto / polluite et cunctas Erebi consumite poenas! - Teseo ha ora assunto su di sé la responsabilità stessa della voce epica giudicante. Non c'è nulla, qui, dell'esitazione e della scelta tragica di Enea di fronte a Turno humilis e supplex; in sé, l'uccisione di Creonte è un legittimo tirannicidio. L'unica colpa che non merita clemenza, sembra dire Stazio, è l'inclemenza di un tiranno: che merita il gesto clemente della sepoltura, ma va punita sulla terra con la morte, e va affidata oltre la morte all'inclemente punizione divina.

Questo complesso di motivi è già raccolto intorno alla figura di Teseo nell'Hercules furens $^{88}$. Ercole sta uccidendo fuori scena il tiranno Lico; mentre copre l'amico, Teseo racconta, ad Anfitrione e al pubblico, il viaggio nell'Ade, da cui l'eroe lo ha liberato; al centro del racconto, inizia ad effetto a illustrare i castighi infernali dalla punizione dei tiranni. Digressione narrativa e azione drammatica si corrispondono ${ }^{89}$ (e giustizia divina e azione di un giustiziere umano appaiono, almeno in questo caso, alleate). Il valore esemplare riconosciuto ai castighi dei re (fin da Platone) ${ }^{90}$ è sfruttato qui per rivolgere, con la voce di Teseo, un ammonimento diretto a chi regna: perché usi moderazione e mitezza, si astenga dal sangue e dall'ira, in una parola - una parola che nelle tragedie Seneca non usa - eserciti clemenza; sono i versi 735-47:

quod quisque fecit, patitur; auctorem scelus

repetit suoque premitur exemplo nocens:

vidi cruentos carcere includi duces

et impotentis terga plebeia manu

scindi tyranni. quisquis est placide potens

dominusque vitae servat innocuas manus

et incruentum mitis imperium regit

animoque parcit, longa permensus diu

felicis aevi spatia vel caelum petit

vel laeta felix nemoris Elysii loca,

iudex futurus. sanguine humano abstine

quicumque regnas: scelera taxantur modo

maiore vestra.

L'esortazione al buon governo sembra tolta al De clementia (i paralleli sono noti) ${ }^{91}$; e tocca a Teseo formularla: in quanto testimone delle pene infernali, ma anche in quanto figura pubblica e politica, re fondatore e rappresentante della civiltà ateniese (un ruolo che sarà in evidenza nel finale $)^{92}$. L'eccezionalità dell'ammonimento diretto al pubblico, isolato nel teatro senecano all'infuori dei cori, segnala l'importanza del motivo. La condanna della tirannia e l'elogio della sovranità clemente sono due aspetti complementari, proprio come nella Tebaide; e, come nella Tebaide, tocca a Teseo proporre un ideale politico positivo, che è caso unico nelle tragedie senecane.Il Teseo della Tebaide trova in Seneca, come nelle Supplici, un modello tragico dal potenziale positivo, che può essere valorizzato nel finale dell'epos.

\section{La 'clementia' di Teseo in battaglia}

Vorrei infine esaminare, come emblematica della compresenza di esemplarità e pessimismo nella chiusa, una delle similitudini che accompagnano Teseo in battaglia: un paragone che illustra la condotta dell'eroe in combattimento con un tradizionale exemplum di clementia. 
70 La guerra degli Ateniesi contro i Tebani è, in Stazio, una guerra-non-guerra ${ }^{93}$ : il distacco dalle Supplici è anche qui significativo. Il paradosso è ancora una volta la cifra del racconto: la battaglia si profila da subito come uno scontro impari, addirittura senza storia, a differenza dello scontro ad armi pari, e a fasi alterne, narrato dal messaggero in Euripide ${ }^{94}$; l'aver messo a contatto diretto la materia delle Supplici con quella delle Fenicie produce effetti dirompenti sulla rappresentazione bellica. Programmatico è già il commento d'autore al disperato ordine di riarmarsi emanato da Creonte di fronte all'ultimatum, armari populos tamen armaque ferri / ipse iubet pallens (12, 694-5): 12, 698-9 quis fuit ille dies, tanto cum sanguine Thebis / pax inventa perit!; un'esclamazione simpatetica, cui seguono una scena di vestizione delle armi pietosa e paradossale (699-708 patriis modo fixa revellunt / arma deis, clipeisque obducunt pectora fractis, / et galeas humiles et adhuc sordentia tabo / spicula: non pharetris quisquam, non ense decorus, / non spectandus equo; cessat fiducia valli, / murorum patet omne latus, munimina portae / exposcunt: prior hostis habet; fastigia desunt: / deiecit Capaneus) e la versione in negativo di un'altra scena tipica dell'epos, tante volte declinata nella Tebaide, quella degli addii: 706-8 exanguis et aegra iuventus / iam nec coniugibus suprema nec oscula natis / iungit, et attoniti nil optavere parentes - un quadro in marcato contrasto con lo slancio eroico degli Ateniesi in 12, 639-41 hos ubi velle acies et dulci gliscere ferro / dux videt, utque piis raptim dent oscula natis / amplexusque breves, curru sic fatur ab alto... È sintomatico del pathos, dei paradossi e del pacifismo della Tebaide che la giusta guerra di Teseo colpisca un popolo descritto con enfasi come stanco di guerra, desideroso di pace e costretto ancora una volta a combattere per volontà del tiranno: la complessità tragica delle Supplici è così ulteriormente ed originalmente approfondita.

71 La disparità tra i due eserciti diventa visibile quando si giunge al confronto diretto sul campo: 12, 720-25 iamque alternas in proelia gentes / dissimilis Bellona ciet; non clamor utrimque, / non utrimque tubae: stat debilis altera pubes / summissos enses nequiquam ammentaque dextris / laxa tenens; cedunt tellure, armisque reductis / ostentant veteres etiamnum in sanguine plagas. In questa patetica asimmetria, i Tebani, più che in assetto di guerra, appaiono quasi nell'atteggiamento di una miseratio, ostentando di fronte agli avversari le ferite della guerra recente. Quella visione produce sulle truppe ateniesi un effetto disarmante: 726-29 iam nec Cecropiis idem ductoribus ardor, / languescuntque minae et virtus secura residit: / ventorum velut ira minor, nisi silva furentes / impedit, insanique tacent sine litore fluctus. L'impeto eroico che ha impresso fin qui un movimento rapido alla narrazione si smorza di colpo, e il fervore ideale che ha indirizzato ogni sforzo contro il tiranno si trova a fronteggiare la realizzazione di una guerra contro un popolo che del tiranno appare vittima.

Fermiamoci un momento su questi versi. Una tensione problematica tra linguaggio bellico e linguaggio dell'etica si coglie in questa descrizione; virtus è il valore militare che si affievolisce negli Ateniesi, ma l'espressione virtus secura residit attiva un corto circuito (di cui non è facile fissare il senso) con formule stoicheggianti: virtus... residit suggerisce, quasi paradossalmente in questo contesto, l'infiacchirsi della virtù morale in mancanza di un ostacolo (marcet sine adversario virtus, Sen. prov. 2, 4), mentre virtus secura fa pensare al tranquillo conformarsi del saggio al destino, e questo attraverso il ricordo e il rovesciamento della clausola lucanea con cui Catone giustificava, all'opposto, la sua partecipazione alla guerra civile (Luc. 2, 286-7 'summum, Brute, nefas civilia bella fatemur; / sed quo fata trahunt, virtus secura sequetur. / crimen erit superis et me fecisse nocentem'). Una serie di interferenze disturbanti, forse previste dall'autore, 
complica così la nostra ricezione del testo staziano, e lascia aperti interrogativi sullo statuto morale dell'impresa ateniese.

Anche la similitudine che segue è ambigua; i termini ira, furentes, insani rispecchiano nella descrizione naturalistica il furor bellico, che l'esitazione delle truppe per un momento tiene lontano: è come se fosse affidato all'illustrans, in una sorta di controcanto, il commento alla follia della guerra, anche di una guerra giusta come questa. Stazio rielabora qui una similitudine con cui Lucano illustrava, attraverso le stesse parole del condottiero, la smania di guerra di Cesare; un'immagine interpretata appunto come "la versione 'satanica' [...] del motivo secondo il quale la virtù, per consolidarsi, ha bisogno di temprarsi continuamente nella lotta contro le avversità" 95 : Luc. 3, 362 ss. 'ventus ut amittit vires, nisi robore densae / occurrunt silvae, spatio diffusus inani, / utque perit magnus nullis obstantibus ignis, / sic hostes mihi desse nocet, damnumque putamus / armorum, nisi qui vinci potuere rebellant ${ }^{96}$. Variando il duplice comparatum, il poeta flavio ripropone il paragone in una situazione rovesciata e in un contesto di tono opposto: se l'ira di Cesare si scagliava contro la proposta di pace degli abitanti di Marsiglia, qui è invece lo stesso tiranno di Tebe ad aver reso vano il desiderio di pace del suo popolo e a rappresentare, in ultima analisi, il vero responsabile della guerra; mentre quello che, nella Pharsalia, era un violento rammarico espresso dal condottiero per la quiete forzata diventa, qui, una descrizione oggettiva del momentaneo placarsi delle truppe di Teseo, di fronte a un nemico quasi inerme. Tuttavia, l'immagine lucanea torna a rendere più complessa la nostra percezione delle circostanze narrative, e a problematizzare l'intervento ateniese che il testo di Stazio apertamente giustifica: il fondo amaro del poema emerge, anche in questo finale che dovrebbe trasformarlo in un'epica dei vincitori ${ }^{97}$.

È dunque una guerra-non-guerra quella che si annuncia, attraverso gli elementi di una descrizione paradossale: un esercito senza forze, una vestizione anomala, un addio mancato, un segnale privo di suono, uno schierarsi a chiedere pietà, il ritirarsi prima di cominciare, lo spiazzamento degli avversari. Quando infine Teseo solleva la lancia, la sua sola ombra ha già messo in fuga i Tebani. La similitudine che paragona l'eroe a Marte, impugnata dalla critica pessimista come prova della colpevole violenza di Teseo, apre la strada, al contrario, a una rappresentazione (anch'essa fuori dal comune) dell'aristia misurata e della calcolata moderazione dell'eroe in battaglia ${ }^{98}$. La movenza comparativo-ipotetica fa vedere l'immagine incombente di Teseo-Marte dal punto di vista dei Tebani atterriti, mentre l'eroe, con il suo comportamento, subito dopo la smentisce, sdegnando di inseguire i nemici che la sua sola vista ha messo in fuga: 12 , 730-37 ut vero aequoreus quercum Marathonida Theseus / extulit, erectae cuius crudelis in hostes / umbra cadit campumque trucem lux cuspidis implet, / ceu pater Edonos Haemi de vertice Mavors / impulerit currus, rapido mortemque fugamque / axe vehens, sic exanimis in terga reducit / pallor Agenoridas ${ }^{99}$. taedet fugientibus uti / Thesea, nec facilem dignatur dextra cruorem... C'è una voluta corrispondenza a contrasto con l'unica similitudine con Marte nell'Eneide, intenzionalmente riservata da Virgilio a connotare, nel dodicesimo libro, la violenza di Turno ${ }^{100}$ : un paragone crudo per un'aristia sanguinosa ed insistita, in cui l'eroe travolge col carro i nemici, li incalza nella fuga, ne calpesta i cadaveri, strappando all'autore un commento patetico $(12,329-30$ seminecis volvit multos: aut agmina curru / proterit aut raptas fugientibus ingerit hastas... 338-9 miserabile caesis / hostibus insultans). Silio seguirà Stazio nel restituire la similitudine a una funzione non 
distanziante, la trasformerà anzi in un elemento apertamente celebrativo, paragonando Scipione a Marte nella battaglia finale dei Punica ${ }^{101}$.

L'effettivo comportamento di Teseo, in Stazio, è ritratto da un'altra similitudine, subito successiva, che oppone al superiore disdegno del capo l'impegno del resto delle truppe a far strage di nemici: $12,736-40$

taedet fugientibus uti

Thesea, nec facilem dignatur dextra cruorem;

cetera plebeio desaevit sanguine virtus:

sic iuvat exanimis proiectaque praeda canesque

degeneresque lupos, magnos alit ira leones.

Osserviamo la sequenza narrativa. Stazio modella il racconto sul finale dell'Eneide. Il rifiuto di inseguire i nemici in fuga, detto con nec... dignatur, è un primo segnale che allinea Teseo ad Enea: Verg. Aen. 12, 462-7 tollitur in caelum clamor, versique vicissim / pulverulenta fuga Rutuli dant terga per agros. / ipse neque aversos dignatur sternere morti / nec pede congressos aequo nec tela ferentis / insequitur: solum in densa caligine Turnum / vestigat lustrans, solum in certamina poscit. Tornato in campo e deciso a far rispettare infine il patto del duello, Enea non si cura, non solo di colpire a morte i nemici che fuggono (aversos), ma neppure di inseguire chi cerca lo scontro ad armi pari o chi gli scaglia giavellotti da lontano: il suo unico scopo è ormai affrontare Turno (solum... Turnum... solum) e porre fine alla guerra. Solo in seguito, frustrato da Giuturna e provocato da Messapo, l'eroe torna a combattere e sfoga la sua ira contro tutti i Latini: un furor che Virgilio ha cura di giustificare, ma che dà luogo a una strage indiscriminata, in un'aristia parallela a quella di Turno, e provoca una inquieta domanda sulla teodicea (Aen. 12, 493-504).

Nella Tebaide, a battaglia appena iniziata, anche Teseo non si cura di approfittare dei nemici in fuga né si degna di spargere sangue "facile", taedet fugientibus uti / Thesea nec facilem dignatur dextra cruorem (mentre su sangue "comune", di Tebani qualsiasi, infieriscono i suoi) ${ }^{102}$. Anche Teseo, e qui fin dall'inizio, ha di mira il solo Creonte, come Stazio dirà ripetendo l'anafora virgiliana ai vv. $752-3$ sed solum votis, solum clamore tremendo / omnibus in turmis optat vocitatque Creonta ${ }^{103}$. Tra questi due momenti, tuttavia (attamen 12, 741), l'eroe ateniese soddisfa nel testo di Stazio i requisiti minimi di una battaglia epica, con un'aristia di undici versi (12, 741 ss. attamen Olenium Lamyrumque, hunc tela pharetra / promentem, hunc saevi tollentem pondera saxi / deicit...): il minimo indispensabile, inserito con precisione chirurgica nel taglio praticato sul modello virgiliano ${ }^{104}$. Nella cornice di quei quattro versi dell'Eneide viene così interpolata un'aristia in miniatura: sei nomi in tutto, pochi dettagli, un catalogo essenziale ${ }^{105}$; sarebbe difficile, su questa base, sostenere che Stazio abbia ritratto un eroe in preda a smania di guerra ${ }^{106}$.

Più ancora che nell'Eneide, centro esclusivo dell'interesse è qui il duello. E di fronte al tiranno, nel disegno rapido e stilizzato della Tebaide, Teseo sarà un Enea senza esitazioni: anche lui assimilato implicitamente a Giove (Theb. 12, 770-1 nec non prius ore superbo / intonat; Aen. 12, 700 horrendumque intonat armis), anche lui impegnato in un atto sacrificale (Theb. 12, 771 'Argolici, quibus haec datur hostia, manes'; Aen. 12, 948-9 'Pallas te hoc volnere, Pallas / immolat...'), anche lui vendicatore di un sangue scellerato, ma questa volta definito "empio" col suggello oggettivo della voce autoriale (Theb. 12, 776-7 emicuit per mille foramina sanguis / impius; Aen. 12, 949 '...et poenam scelerato ex sanguine sumit') $)^{107}$. 
Torniamo ora ai versi illustrati dalla similitudine. Disdegnare di colpire un nemico mentre fugge è un tratto di eroismo nobile, che Virgilio attribuisce anche a Mezenzio in Aen. 10, 732 ss. atque idem fugientem haud est dignatus Oroden / sternere nec iacta caecum dare cuspide vulnus... - ma se Mezenzio insegue il nemico per combatterlo a viso aperto, Teseo si limita ad affrontare i pochi rimasti a resistergli. Nel testo di Stazio, il rifiuto di Teseo di "approfittare" (uti) della fuga dei Tebani sembra inoltre correggere un'immagine ovidiana, nel racconto della Centauromachia affidato alla voce di Nestore: Ov. met. 12, $355 \mathrm{~s}$. haud tulit utentem pugnae successibus ultra / Thesea Demoleon; a un Teseo indefesso e compiaciuto dei propri successi, nella lotta contro creature mostruose, si contrappone qui un Teseo moderato nell'infierire sui sudditi di Creonte.

La moderazione mostrata da Teseo in battaglia ha un precedente importante nelle Supplici ${ }^{108}$. Nella tragedia il diverso tenore dello scontro provoca in una prima fase un'esibizione più eclatante del valore dell'eroe, ma ad essa segue infine, con un contrasto voluto, una prova decisiva di autocontrollo e di senso della misura ${ }^{109}$. I due momenti sono accompagnati da due tratti metanarrativi, due commenti simmetrici del messaggero che lodano, prima il coraggio, poi la moderazione del capo. Il primo elogio,

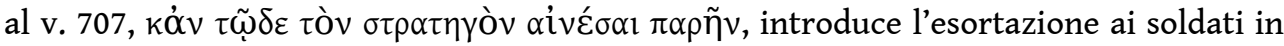
difficoltà e l'aristia di Teseo, armato di clava, che mette infine in fuga i nemici (718 ss.

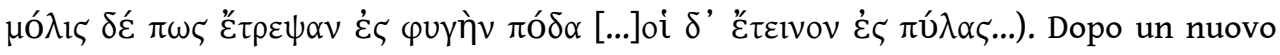
intervento del comandante, che trattiene le truppe dal devastare Tebe e dichiara di essere venuto non per saccheggiare una città, ma per chiedere la restituzione delle

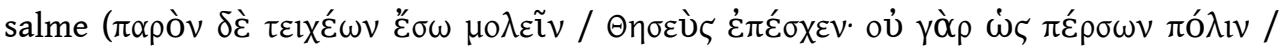

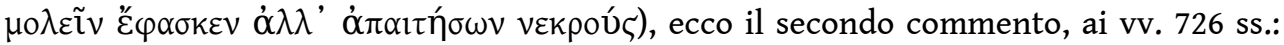

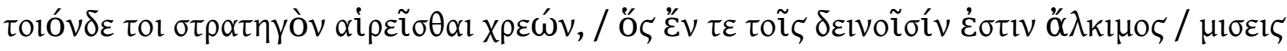

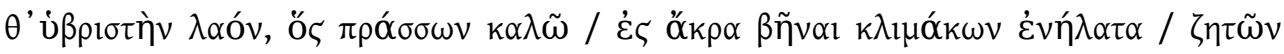

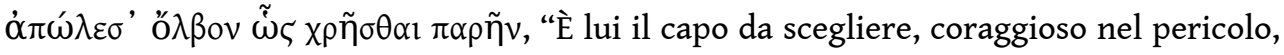
ma nemico della massa tracotante, di quanti, fortunati, cercano di salire sui pioli della scala sino alla cima, e perdono così la fortuna già acquisita" (trad. U. Albini). È il ritratto di un comandante ideale - se non addirittura un "appello elettorale" - quello che viene proposto nelle parole del messaggero ${ }^{110}$; a questo profilo di un capo democratico moderato, e immune da demagogia, Stazio sostituisce il modello imperiale della clementia, condensandolo in un'immagine emblematica.

Valore e moderazione insieme: sono queste, in dosi e rapporti diversi, le qualità anche del Teseo della Tebaide, che - tratto eccezionale - subito dopo la rapida vittoria non solo non deve dissuadere i suoi dal saccheggio, ma è acclamato dai nemici come un liberatore e accolto in città come un ospite. Costruendo un eroe teso solo al tirannicidio, Stazio ha rappresentato la moderazione di Teseo già sul campo, nel corso stesso della battaglia, e ne ha fatto, ancor prima della vittoria, un modello di clementia verso i nemici, prima ancora che verso i vinti (un atteggiamento che può ricordare l'ordine di Cesare, nella guerra civile, di risparmiare i concittadini volti in fuga: esempio di clemenza passato nell'aneddotica, testimoniato da Svetonio, Appiano, Floro, e aggredito dal sarcasmo di Lucano) ${ }^{111}$.

Nel testo staziano il commento alla misura di Teseo in battaglia è affidato all'evidenza di un'immagine: una comparazione che si offriva al poeta flavio già carica di significati ideologici. La similitudine col comportamento del leone verso la preda, contrapposto a quello dei cani e dei lupi, ripropone qui la materia più tipica delle similitudini epicoomeriche in una forma che alla tradizione epica è estranea. Rivelatore è l'impianto 
stesso del paragone, argomentativo e dimostrativo piuttosto che descrittivo: il dittico animale, più che dipingere una scena, delinea un contrasto 'etico'. Il modello di Stazio non si trova nella poesia omerica, ma nella tradizione delle esortazioni alla clementia (e potrebbe far pensare a una tradizione retorica, di scuola): l'immagine del leone che sdegna di accanirsi sulla preda abbattuta è il correlativo animale dello slogan bellante prior, iacentem / lenis in hostem, coniato da Orazio per la clemenza di Augusto (carm. saec. 51-2).

83 È proprio delle bestie ignobili accanirsi sulla preda stesa a terra, mentre leoni ed elefanti trascurano le loro vittime dopo averle abbattute: così Seneca, nel De clementia, illustrava con esempi animali il concetto di magnanimità ${ }^{112}$; Sen. de clem. 1, 5, 5 Magnam fortunam magnus animus decet [...] magni autem animi proprium est placidum esse tranquillumque et iniurias atque offensiones superne despicere. Muliebre est furere in ira, ferarum vero et $<n e>$ generosarum quidem praemordere et urguere proiectos. Elephanti leonesque transeunt, quae impulerunt; ignobilis bestiae pertinacia est (si noti proiecta: lo stesso termine impiegato da Stazio).

La contrapposizione fra il leone "magnanimo" e animali meno nobili aveva già trovato forma poetica nell'Ovidio dell'esilio, in una serie di exempla di magnanimità, clemenza, capacità di placare la propria ira tratti anche dal mito e dalla storia. Il leone si accontenta di abbattere la preda, mentre lupi, orsi ed altre fiere ignobili infieriscono sui morenti: Ov. trist. 3, 5, 31 ss. quo quisque est maior, magis est placabilis irae, / et faciles motus mens generosa capit. / corpora magnanimo satis est prostrasse leoni, / pugna suum finem, cum iacet hostis, habet. / at lupus et turpes instant morientibus ursi, / et quaecumque minor nobilitate fera est. / maius apud Troiam forti quid habemus Achille? / Dardanii lacrimas non tulit ille senis. / quae ducis Emathii fuerit clementia, Porus / Dareique docent funeris exequiae. / neve hominum referam flexas ad mitius iras, / Iunonis gener est qui prior hostis erat. Il poeta sta suggerendo all'amico (forse il poeta Caro), distinto per le sue doti oratorie, gli argomenti di un discorso persuasivo con cui predisporre Augusto alla clementia (28-30 ...tu mihi, quod cupio, fas, precor, esse proba, / quaeque tibi est linguae facundia, confer in illud, / ut doceas votum posse valere meum); il paradigma animale è parte di un pezzo già retoricamente elaborato, che dovrebbe indurre il principe a non infierire sul poeta: la condanna all'esilio può ora essere mitigata con la scelta di un luogo di pena meno ostile.

Il motivo del leone clemente, estraneo a Omero $^{113}$ e presente nella tradizione favolistica ${ }^{114}$, è recepito anche nell'enciclopedia di Plinio: Plin. nat. 8, 48 Leoni tantum ex feris clementia in supplices; prostratis parcit et, ubi saevit, in viros potius quam in feminas fremit, in infantes non nisi magna fame. Credit Libya pervenire intellectum ad eos precum... Una sua diffusione come exemplum nella tradizione retorica sembra testimoniata da [Quint.] decl.mai. 9, 18 Age, si perisset, cadaver calcasses? Ferae mehercules generosiores iacentes transeunt, et, <cum> reservati hostes restitutaeque urbes maiora causae exempla sint, quod scio, victis etiam gladiatores parcunt. Al tema della clemenza si unisce, nel testo di Stazio, la sottolineatura dell'ira come tratto di nobiltà dell'animale (magnos alit ira leones), in quanto impeto che si placa dopo il primo slancio: un aspetto non estraneo alla discussione filosofica, come mostra la polemica di Sen. de ira 3, 16 ('Animalia' inquit 'generosissima habentur quibus multum inest irae' [...] iracundia leones adiuvat [...] Quid quod ne illud quidem verum est, optima animalia esse iracundissima?...). Tradizioni culturali diverse collaborano dunque a fare del leone un esempio di bilanciamento tra ira e clementia ben adatto ad essere proposto all'autorità politica. 
86 Nel testo di Stazio l'insieme di similitudine e referente narrativo suggerisce la compresenza di due aspetti: il disdegno di una preda facile e comune (nec facilem dignatur... cruorem; plebeio... sanguine) e il rifiuto di accanirsi sulla preda abbattuta e inerme (exanimis proiectaque praeda). Questa combinazione di motivi tornerà più di una volta in Claudiano, memore di questo e di altri passi di Stazio, oltre che dei versi di Ovidio. Il leone che cerca lo scontro col toro, ma trascura prede "umili" e "atterrate", è uno dei modelli di comportamento che la Clementia insegna a Stilicone, nell'elogio di Claud. Stil. 2, $12 \mathrm{ss}$. haec dea [sc. Clementia] pro templis et ture calentibus aris / te fruitur posuitque suas hoc pectore sedes. / haec docet ut poenis hominum vel sanguine pasci / turpe ferumque putes; ut ferrum Marte cruentum, / siccum pace feras; ut non infensus alendis / materiem praestes odiis; ut sontibus ultro / ignovisse velis, deponas ocius iram / quam moveas, precibus numquam inplacabilis obstes, / (20 ss.) obvia prosternas, prostrataque more leonum / despicias, alacres ardent qui frangere tauros, / transiliunt praedas humiles. hac ipse magistra / das veniam victis...115. La stessa immagine è impiegata dal poeta nella Deprecatio ad Hadrianum per indurre il magister officiorum a un comportamento clemente nei suoi confronti: responsabile di un'offesa, Claudiano ha perduto il favore del patrono e, caduto in disgrazia, lo esorta ora a non accanirsi indegnamente contro un inferiore: carm. min. 22, 11 ss. excessit iam poena modum. concede iacenti. / en adsum; veniam confessus crimina posco. / manibus Hectoreis atrox ignovit Achilles [...] quid superest damnis? quae saeva pericula restant? / (27 ss.) emollit rabiem praedae mortisque facultas. / praetereunt subiecta ferae, torvique leones, / quae stravisse calent, eadem prostrata relinquunt / nec nisi bellantis gaudet cervice iuvenci / nobiliore fames... ${ }^{116}$.

87 Il tema era dunque già divenuto (e sarebbe rimasto) tradizionale nel discorso politico, in sede di definizione teorica e di esortazione alla clementia. È però in età flavia, in ambito vicino a Stazio, che troviamo una declinazione per noi ancora più interessante del motivo. Si tratta del 'ciclo delle lepri e dei leoni' nel primo libro di Marziale: la nota serie di epigrammi, ben studiata anche in tempi recenti, che commenta uno spettacolo dell'anfiteatro dal chiaro valore propagandistico ${ }^{117}$. Il leone che gioca, mite e inoffensivo, con le lepri - prede piccole, imbelli, indegne del re degli animali - offre agli spettatori una rappresentazione simbolica della clemenza dell'imperatore (e può apparire come una manifestazione della sua potenza divina, estesa al controllo sulla natura). Il poeta si fa tramite del messaggio politico dei giochi presso il pubblico dei lettori e si propone come 'interprete creativo' dell'ideologia imperiale: traducendo i valori simbolico-visuali nel discorso poetico, invita a sottomettersi con fiducia a un potere protettivo verso i deboli, temibile verso i forti - ripropone insomma, nelle forme e nella misura minore dell'epigramma, il virgiliano parcere subiectis et debellare superbos ${ }^{118}$.

Un epigramma del ciclo, in particolare, è notevole in relazione al nostro discorso, non solo perché presenta la stessa contrapposizione tra leone e cani della similitudine di Stazio, ma perché lega in modo diretto ed esplicito il tema della mitezza verso la preda piccola, e della minaccia per le prede grandi, alla clementia di Domiziano nelle campagne militari contro i Daci (siamo probabilmente nell'85/86 d.C.): Mart. 1, 22 quid nunc saeva fugis placidi lepus ora leonis? / frangere tam parvas non didicere feras. / servantur magnis isti cervicibus ungues / nec gaudet tenui sanguine tanta sitis. / praeda canum lepus est, vastos non implet hiatus: / non timeat Dacus Caesaris arma puer ${ }^{119}$.

89 Stazio sfrutta dunque nel contesto epico un'immagine densa di implicazioni ideologicopolitiche; con uno spostamento agevole, la piega ad illustrare una situazione bellica, 
restituendo l'analogia animale al ruolo ad essa consueto nella tradizione epico-omerica. Il 'moderno' paradigma etico del leone-imperatore-clemente si sovrappone così al cliché omerico del guerriero-leone, risultando in rapporto di perfetta omologia e di 'corrispondenza multipla' col referente narrativo della battaglia ${ }^{120}$.

Il paragone impiegato per Teseo si inserisce in una costellazione di similitudini col leone distribuita nella Tebaide secondo un disegno significativo ${ }^{121}$. La comparazione con la più forte delle fiere è spesso utile al poeta epico (non diversamente che nella tradizione omerica) per commentare i rapporti di forze tra i combattenti. Capaneo che attacca l'imbelle sacerdote di Bacco, e gioisce dello scontro impari, è come un leone che al mattino sfoga la prima fame su un cervo o su un giovenco ancora privo di corna ${ }^{122}$. Il giovane Atys che inizia a far strage di schiere "facili" è come un leone ancora privo di criniera, e ancora ignaro del sangue di prede grandi (magnique etiamnum sanguinis insons), che assale un gregge indifeso e sbrana una tenera agnella; per contro Tideo, che non degna il giovane se non di una freccia noncurante (ma per lui mortale), è come un leone già sazio, che trascura vitelli e giovenche e cerca il sangue di prede grandi (magno furor est in sanguine mergi), il toro sovrano ${ }^{123}$.

91 Altrove Stazio valorizza invece, più in particolare, la pertinenza dell'immagine del leone al discorso della clemenza. Il re degli inferi, Plutone, nel momento in cui si piega sdegnoso alla supplica di Anfiarao, è paragonato al leone che, una volta abbattuto l'uomo nemico, placa la propria ira e gli risparmia la vita: Theb. 8, 123-6 accipit ille preces indignaturque moveri. / ut leo, Massyli cum lux stetit obvia ferri, / tunc iras, tunc arma citat; si decidit hostis, / ire supra satis est vitamque relinquere victo ${ }^{124}$. È un paradosso caratteristico della Tebaide che l'inflessibile sovrano dell'Ade non solo si lasci vincere dalle preghiere (come di fronte a Orfeo in Virgilio e Ovidio), ma venga addirittura costruito come un modello di sovranità clemente ${ }^{125}$.

92 La similitudine impiegata per Teseo in battaglia aggiunge dunque un altro tratto all'esemplarità dell'eroe ${ }^{126}$, ma è in pari tempo emblematica del pessimismo della Tebaide: mentre esalta la moderazione del sovrano ateniese, mette in evidenza, per contrasto, la furia bellica dei suoi compagni. Il senso di sospensione del furor, creato poco prima dal paragone col placarsi degli elementi, qui si spezza: la designazione delle truppe come cetera virtus richiama il precedente virtus secura residit, mentre il nesso desaevit sanguinevirtus, giocando di nuovo sullo iato tra virtus militare e morale, fa stridere, in un contatto ossimorico, crudeltà e virtù ${ }^{127}$. Stazio descrive l'infuriare dei soldati ateniesi con il composto intensivo che Virgilio usava per Enea nella sua aristia più brutale, nel momento in cui lo paragonava al gigante Egeone: Aen. 10, 569 sic toto Aeneas desaevit in aequore victor / ut semel intepuit mucro ${ }^{128}$; il contatto con uno dei punti più problematici dell'Eneide fa sentire, anche qui, la tragedia di una guerra sia pure legittima. Anche la sottolineatura del carattere comune delle vittime (plebeio), mentre fa risaltare la clemenza di Teseo che le ignora, suggerisce il carattere indiscriminato della strage compiuta dal resto delle truppe; è un tratto che può ricordare la problematica aristia di Eurialo contro una massa senza nome, multam... sine nomine plebem - Eurialo paragonato, come Niso, a un leone digiuno e omericamente affamato che fa strage di prede imbelli ${ }^{129}$.

93 Se torniamo per un attimo al passo delle Supplici, la differenza di prospettiva salta agli occhi: là il pregio di un capo democratico veniva fatto risiedere nella capacità di trattenere il "popolo arrogante"; nella visione imperiale di Stazio, tutto l'interesse si 
concentra sul capo, e quel che più conta è disegnare il profilo ideale di un solo uomo, a tutti superiore: il modello del sovrano.

È la relazione con un altro luogo della Tebaide, infine, a completare il senso del nostro passo. All'inizio dell'undicesimo libro il fulmine scagliato da Giove contro Capaneo mette in fuga gli Argivi, e i Tebani ne approfittano. Una similitudine simmetrica a quella del finale illustra la situazione: il leone, dopo aver abbattuto dei tori, re degli armenti, se ne va soddisfatto, ed è allora che orsi e lupi arrivano, senza slancio d'ira, ignobili, a leccare le ferite di una preda altrui; Theb. 11, 21 ss. at vaga pallentes campo fuga volvit Achivos. / nec iam hostes turmae aut ferrum mortale timetur: / omnibus ante oculos irae Iovis, omnibus ardent / arma metu galeaeque tonant, visusque paventes / ipse sequi et profugis opponere Iuppiter ignis. / instat Agenoreus miles caelique tumultu / utitur: indomitos ut cum Massyla per arva / armenti reges magno leo fregit hiatu / et contentus abit; rauci tunc comminus ursi, / tunc avidi venere lupi, rabieque remissa / lambunt degeneres alienae vulnera praeda $^{130}$. La specularità delle immagini sottolinea l'alternanza di sorti: i Tebani inseguitori sono ora inseguiti; essi che avevano approfittato (utitur) della fuga degli Argivi, causata da Giove, vedono ora approfittare della loro fuga, causata da Teseo, i soldati ateniesi. Ma la correlazione tra le due similitudini provoca anche un altro effetto di senso. Il contrasto tra leone e fiere ignobili torna ad illustrare la sproporzione di valore tra la massa dei soldati e un combattente d'eccezione, che nel libro precedente era addirittura Giove: il parallelismo nobilita Teseo, ma fa scadere gli Ateniesi al livello dei Tebani profittatori.

Esemplarità e pessimismo sono ancora una volta inscindibili nel testo di Stazio: quando la guerra si realizza sul campo - la Tebaide insegna - può diventare difficile distinguere una guerra giusta da una sbagliata.

\section{BIBLIOGRAFIA}

Ahl 1986: F. Ahl, Statius' Thebaid: A Reconsideration, «ANRW» II.32.5, 1986, pp. 2803-2912.

Aloni 2003: A. Aloni, Teseo, un eroe dalle molte identità, in Forme di comunicazione nel mondo antico e metamorfosi del mito: dal teatro al romanzo, a cura di M. Guglielmo e E. Bona, Alessandria 2003, pp. $1-22$.

Adam 1970: T. Adam, Clementia principis, Stuttgart 1970.

Bellincioni 1984: M. Bellincioni, Potere ed etica in Seneca. Clementia e voluntas amica, Brescia 1984.

Bertelli 2003: L. Bertelli, Teseo: un padre nobile per la democrazia ateniese, in E. Luppino Manes (ed.), Storiografia e regalità nel mondo greco, Alessandria 2003, pp. 177-194.

Bertelli - Gianotti 1987: L. Bertelli - G.F. Gianotti, Teseo tra mito e storia politica: un'Atene immaginaria?, «Aufidus» 1, 1987, pp. 35-58.

Bessone 1998: F. Bessone, Valerius Flaccus und die Medeen des Ovid, in 'Ratis omnia vincet'. Neue Untersuchungen zu den Argonautica des Valerius Flaccus, hrsg. von U. Eigler, E. Lefèvre, München 1998, pp. 141-171. 
Bessone 2002:F. Bessone, Voce femminile e tradizione elegiaca nella 'Tebaide' di Stazio, in I 'Sette a Tebe'. Dal mito alla letteratura. Atti del Seminario Internazionale (Torino, 21-22 Febbraio 2001), a cura di A. Aloni, E. Berardi, G. Besso, S. Cecchin, Bologna, 2002, pp. 185-217.

Bessone 2006: F. Bessone, Un mito da dimenticare. Tragedia e memoria epica nella Tebaide, «MD» 56, 2006, pp. 93-127.

Bessone 2008: F. Bessone, Epica e potere. Forma narrativa e discorso politico nella Tebaide di Stazio, in “Arma virumque cano...". L'epica dei Greci e dei Romani, Atti del convegno nazionale dell'A.I.C.C. (Torino, 23-24 aprile 2007), a cura di R. Uglione, Alessandria 2008.

Billerbeck 1999: Seneca, Hercules furens. Einl., Text, Übers. und Komm. von M. Billerbeck, LeidenBoston-Köln 1999.

Burck 1953: E. Burck, Die Schicksalsauffassung des Tacitus und Statius, in Studies Presented to D.M. Robinson on his Seventieth Birthday, II, Saint-Louis 1953, pp. 693-706.

Burck 1979: E. Burck, Die 'Thebais' des Statius, in E. Burck (Hrsg.), Das römische Epos, Darmstadt 1979, pp. 300-51.

Burgess 1972: J.F. Burgess, Statius' Altar of Mercy, «CQ» 22, 1972, pp. 339-349.

Cairns 1989: F. Cairns, Virgil's Augustan Epic, Cambridge 1989.

Calame 1996: C. Calame, Thésée et l'imaginaire athénien: légende et culte en Grèce antique, Lausanne 1996.

Citroni 1975: M. Valerii Martialis Epigrammaton liber primus, Introduzione, testo, apparato critico e commento a cura di M. Citroni, Firenze 1975.

Coleman 2006: Martial, Liber Spectaculorum. Ed. with Introduction, Translation and Commentary by K.M. Coleman, Oxford 2006.

Collard 1975: Euripides, Supplices, ed. with Introduction and Commentary by C. Collard, vol. I, Groningen 1975.

Courtney 1980: A Commentary on the Satires of Juvenal, by E. Courtney, London 1980.

Courtney 1993: The Fragmentary Latin Poets, ed. by E. Courtney, Oxford 1993.

Davis 1994: P.J. Davis, The Fabric of History in Statius' Thebaid, in Studies in Latin Literature and Roman History VII, ed. by C. Deroux, Bruxelles 1994, pp. 464-483.

Delarue 2000: F. Delarue, Stace, poète épique. Originalité et cohérence, Louvain-Paris 2000.

Di Benedetto 1971: V. Di Benedetto, Euripide: teatro e società, Torino 1971.

Dietrich 1999: J.S. Dietrich, Thebaid's Feminine Ending, «Ramus» 28, 1999, pp. 40-53.

Dingel 1974: J. Dingel, Seneca und die Dicthung, Heidelberg 1974.

Dominik 1990: W.J. Dominik, Monarchal Power and Imperial Politics in Statius' Thebaid, in A.J. Boyle (ed.), The Imperial Muse. Ramus Essays on Roman Literature of the Empire. Flavian Epicists to Claudian, Bendigo, 1990, pp. 74-97.

Dominik 1994: W.J. Dominik, The Mythic Voice of Statius. Power and Politics in the Thebaid, LeidenNew York-Köln 1994.

Dominik 2005:W.J. Dominik, Statius, in A Companion to Ancient Epic, ed. by J.M. Foley, Oxford 2005, pp. 514-527. 
Esposito 2002: P. Esposito, La 'strana' battaglia del finale della Tebaide, in Scritti in onore di Italo Gallo, a cura di L. Torraca, Napoli 2002, pp. 265-278.

Fabre-Serris 2000: J. Fabre-Serris, Entre mythe et philosophie: l'impiété des Argonautes et la théorie sénéquienne des âges, in Mythe et/ou philosophie dans les textes grecs et latins sur les origines de l'humanité. Actes des journées d'études des 13 et 14 novembre 1998, éd. par J. Fabre-Serris, Lille 2000 («Uranie» 9), pp. 125-134.

Fantham 1992: Lucan, De bello civili, Book II, ed. by E. Fantham, Cambridge 1992.

Fantham 1995: E. Fantham, The Ambiguity of Virtus in Lucan's Civil War and Statius' Thebaid, «Arachnion» 3, 1995, pp. 1-6 (http://www.cisi.unito.it/arachne/num3/fantham.html).

Fantham 1997: E. Fantham, "Envy and Fear the Begetter of Hate": Statius' Thebaid and the Genesis of Hatred, in S.Morton Braund, C. Gill (edd.), The Passions in Roman Thought and Literature, Cambridge 1997, pp. 185-212.

Fantham 1999: E. Fantham, The Role of Lament in the Growth and Eclipse of Roman Epic, in M. Beissinger, J. Tylus, S. Wofford (edd.), Epic Traditions in the Contemporary World. The Poetics of Community, Berkeley-Los Angeles-London 1999, pp. 221-235.

Feeney 1991: D.C. Feeney, The Gods in Epic. Poets and Critics of the Classical Tradition, Oxford 1991.

Fitch 1987: Seneca's Hercules furens. A Critical Text with Introduction and Commentary, ed. by J.G. Fitch, Ithaca and London 1987.

Forbiger $1875^{4}$ : P. Vergili Maronis Opera, cur. A. Forbiger, Leipzig $1875^{4}$.

Gaertner 2005: Ovid, Epistulae ex Ponto, Book 1, ed. with Introduction, Translation and Commentary by J.F. Gaertner, Oxford 2005.

Galasso 2000: Ovidio, Opere. II.Le Metamorfosi, trad. di G. Paduano, intr. di A. Perutelli, comm. di L. Galasso, Torino 2000.

Ganiban 2007: R.T. Ganiban, Statius and Virgil. The Thebaid and the Reinterpretation of the Aeneid, Cambridge 2007.

Gibson 2006: Statius, Silvae 5. Edited with Introduction, Translation, and Commentary by B. Gibson, Oxford 2006.

Gildenhard-Zissos 2004: I. Gildenhard - A. Zissos, Ovid's 'Hecale': Deconstructing Athens in the Metamorphoses, «JRS» 94, 2004, pp. 47-72.

Griffin 2003: M. Griffin, Clementia after Caesar: from Politics to Philosophy, «Papers of the Langford Latin Seminar» 11, Leeds 2003, pp. 157-182.

Hagedorn 2004: S.C. Hagedorn, Abandoned Women. Rewriting the Classics in Dante, Boccaccio, and Chaucer, Ann Arbor 2004.

Hardie 1993: P. Hardie, The Epic Successors of Virgil. A Study in the Dynamics of a Tradition, Cambridge 1993.

Hardie 1997: P. Hardie, Closure in Latin Epic, in Classical Closure. Reading the End in Greek and Latin Literature, ed. by D.H. Roberts, F.M. Dunn, and D. Fowler, Princeton 1997, pp. 139-162.

Harrison 1991: Vergil, Aeneid 10, with Introd., Transl. and Comm. by S.J. Harrison, Oxford 1991.

Helzle 1996: M. Helzle, Der Stil ist der Mensch. Redner und Reden im römischen Epos, Stuttgart und Leipzig 1996.

Henderson 1991: J.G.W. Henderson, Statius’ Thebaid / Form Premade, «PCPS» 37, 1991, pp. 30-80. 
Henderson 1993: J. Henderson, Form Remade / Statius'Thebaid, in Boyle 1993, pp. 162-192.

Hershkowitz 1995: Patterns of Madness in Statius’ Thebaid, «JRS» 85, 1995, pp. 52-64.

Hershkowitz 1998: D. Hershkowitz, The Madness of Epic. Reading Insanity from Homer to Statius, Oxford 1998.

Hose 2005: Forschungsbericht zu Euripides (I) 1970-2000, hrsg. von M. Hose, «Lustrum» 47, 2005.

Keudel 1970: U. Keudel, Poetische Vorläufer und Vorbilder in Claudians De consulatu Stilichonis. Imitationskommentar, Göttingen 1970.

Konstan 2001: D. Konstan, Pity Transformed, London 2001.

Konstan 2005: D. Konstan, Clemency as a Virtue, «CPh» 100, 2005, pp. 337-346.

Kytzler 1962: B. Kytzler, Gleichnisgruppen in der Thebais des Statius, «Wiener Studien» 75, 1962, pp. 141-160.

Laguna-Mariscal 1992: G. Laguna-Mariscal, Estacio, Silvas III, introducción, edición crítica, traducción y comentario, Madrid 1992.

Lapidge 1979: M. Lapidge, Lucan's Imagery of Cosmic Dissolution, «Hermes» 107, 1979, pp. 344-370.

Lechi 1988: F. Lechi, Piger ad poenas, ad praemia velox: un modello di sovrano nelleEpistulae ex Ponto, «MD» 20-21, 1988, pp. 119-132.

Leigh 1997: M. Leigh, Lucan. Spectacle and Engagement, Oxford 1997.

Lewis 1936: C.S. Lewis, The Allegory of Love, Oxford 1936.

Lorenz 2002: S. Lorenz, Erotik und Panegyrik. Martials Epigrammatische Kaiser, Tübingen 2002.

Lovatt 1999: H. Lovatt, Competing Endings: Re-reading the End of the Thebaid through Lucan, «Ramus» 28, 1999, pp. 126-151.

Mack 1988: S. Mack, Ovid, New Haven, 1988.

Malaspina 2003: E. Malaspina, Pensiero politico ed esperienza storica nelle tragedie di Seneca, in Sénèque le tragique («Entretiens sur l'antiquité classique», Tome L), Vandoeuvres-Genève 2003, pp.

267-307.

Malaspina 2005²: L. Annaei Senecae De clementia libri duo, a cura di E. Malaspina, Alessandria $2005^{2}$.

Markus 2003: D.D. Markus, The Politics of Epic Performance in Statius, in A.J. Boyle - W.J. Dominik (edd.), Flavian Rome. Culture, Image, Text, Leiden - Boston 2003, pp. 431-467.

Markus 2004: D.D. Markus, Grim Pleasures: Statius' Poetic Consolationes, «Arethusa» 37, 2004, pp. 105-135.

McGuire 1990: D.T. McGuire, Textual Strategies and Political Suicide in Flavian Epic, in Boyle 1990 (cf. Dominik 1990), pp. 21-45.

McGuire 1997: D.T. McGuire, Acts of Silence. Civil War, Tyranny, and Suicide in the Flavian Epics, Hildesheim-Zürich-New York 1997.

McNelis 2007: C. McNelis, Statius' Thebaid and the Poetics of Civil War, Cambridge 2007.

Mills 1997: S. Mills, Theseus, Tragedy and the Athenian Empire, Oxford 1997.

Morton Braund 1996: S. Morton Braund, Ending Epic: Statius, Theseus, and a Merciful Release, «PCPS» 42, 1996, pp. 1-23.

Morton Braund 1996b: Juvenal, Satires, Book I, ed. by S. Morton Braund, Cambridge 1996. 
Morton Braund-Gilbert 2003: S.M. Braund, G. Gilbert, An ABC of Epic Ira: Anger, Beasts, and Cannibalism, in Ancient Anger: Perspectives from Homer to Galen («YClS» 32), ed. by S. Morton Braund and G.W. Most, Cambridge 2003, pp. 250-285.

Morton Braund 2006: S. Morton Braund, A Tale of Two Cities: Statius, Thebes, and Rome, «Phoenix» 60, 2006, pp. 259-273.

Morwood 2007: Euripides, Suppliant Women, with Introduction, Translation and Commentary by J. Morwood, Oxford 2007.

Narducci 2002: E. Narducci, Lucano. Un'epica contro l'impero, Roma-Bari 2002.

Narducci 2004: E. Narducci, Lo sfondo cosmico della Pharsalia, in P. Esposito - E. Ariemma, Lucano e la tradizione dell'epica latina, Napoli 2004, pp. 7-20.

Nauta 2002: R.R. Nauta, Poetry for Patrons. Literary Communication in the Age of Domitian, LeidenBoston-Köln 2002.

Nauta 2006: The recusatio in Flavian Poetry, in Flavian Poetry, ed. by R.R. Nauta, H.-J. van Dam, J.J.L. Smolenaars, Leiden-Boston 2006, pp. 21-40.

Newlands 2002: C.E. Newlands, Statius' Silvae and the Poetics of Empire, Cambridge 2002.

Paduano 1966: G. Paduano, Interpretazione delleSupplicidi Euripide, «ASNP», Classe di Lettere e Filosofia, 35, 1966, pp. 193-249.

Pagán 2000: V.E. Pagán, The Mourning After: Statius Thebaid 12, «AJPh» 121, 2000, 423-52.

Pollmann 2004: K.F.L. Pollmann, Statius, Thebaid 12. Introduction, Text, and Commentary, PaderbornMünchen-Wien-Zürich 2004.

Pöschl 1977²: V. Pöschl, Die Dichtkunst Virgils. Bild und Symbol in der Äneis, Berlin-New York 1977³.

Raaflaub 2003: K.A. Raaflaub, Stick and Glue: the Function of tyranny in Fifth-century Athenian Democracy, in K. Morgan (ed.), Popular Tyranny: Sovereignity and its Discontents in Ancient Greece, Austin 2003, pp. 59-92.

Reussner 1921: A. Reussner, De Statio et Euripide, Diss. Halle 1921.

Ricci 1998: M.L. Ricci, Il carme minore 22 di Claudiano e l'Ovidio dell'esilio, «Invigilata lucernis» 20, 1998, pp. 221-228.

Ricci 2001: Claudii Claudiani Carmina minora, introduzione, traduzione e commento a cura di M.L. Ricci, Bari 2001.

Rieks 1967: R. Rieks, Homo, Humanus, Humanitas. Zur Humanität in der lateinischen Literatur des ersten nachchristlichen Jahrhunderts, München 1967.

Ripoll 1998: F. Ripoll, La Thébaïde de Stace entre épopée et tragédie, «Pallas» 49, 1998 (Rome et le tragique, ed. par M.-H. Garelli-Francois), pp. 323-340.

Ripoll 1998b: F. Ripoll, La morale hérö̈ue dans les épopées latines d'époque flavienne: tradition et innovation, Louvain-Paris 1998.

Rosati 2002: G. Rosati, Muse and Power in the Poetry of Statius, in Cultivating the Muse. Struggles for Power and Inspiration in Classical Literature, ed. by E. Spentzou and D. Fowler, Oxford 2002, pp. 229-251.

Rosati 2006: G. Rosati, Luxury and Love: the Encomium as Aestheticisation of Power in Flavian Poetry, in Flavian Poetry, ed. by R.R. Nauta, H.-J. van Dam, J.J.L. Smolenaars, Leiden-Boston 2006, pp. 41-58. 
Rosati 2008*: G. Rosati, Statius, Domitian and Acknowledging Paternity. Rituals of Succession in the Thebaid, in corso di stampa in Flavian Poetry. II, ed. by R.R. Nauta, H. van Dam, H. Smolenaars (atti del simposio di Amsterdam 2006).

Smolenaars 1994: P.P. Statius,Thebaid VII. A Commentary, by J.J.L. Smolenaars, Leiden-New YorkKöln 1994.

Timpanaro 1981: S. Timpanaro, Un nuovo commento all'Hercules furens di Seneca nel quadro della critica recente, «Atene e Roma» n.s. 26, 1981, pp. 113-141.

Torre 1995: C. Torre, La concezione senecana del sapiens: le metamorfosi animali, «Maia» 47, 1995, pp. 349-378.

Traina 1998: A. Traina, Poeti latini (e neolatini). Note e saggi filologici V, Bologna 1998.

Venini 1970: P. Papini Stati Thebaidosliber XI, a cura di P. Venini, Firenze 1970.

Vessey 1973: D. Vessey, Statius and the Thebaid, Cambridge 1973.

Vinchesi 2001: Silio Italico,Le guerre puniche, introduzione, traduzione e note di M.A. Vinchesi, 2 voll., Milano 2001.

Vogt 2008: K.M. Vogt, Law, Reason, and the Cosmic City. Political Philosophy in the Early Stoa, Oxford 2008.

Walker 1995: H.J. Walker, Theseus and Athens, New York-Oxford 1995.

Wallace-Hadrill 1981: A. Wallace-Hadrill, The Emperor and his Virtues, «Historia» 30, 1981, pp. 298-319.

Weinreich 1928: O. Weinreich, Studien zu Martial, Stuttgart 1928.

Weinreich 1931 = 1973: O. Weinreich, Zu Babrios 107 und Martial 1, 22, «Philologus» 86, 1931, pp. 370-2 = Ausgewählte Kleine Schriften II (1922-1937), Amsterdam 1973, pp. 391-2.

Zeitlin 1990 (= 1986): F.I. Zeitlin, Thebes: Theater of Self and Society in Athenian Drama, in J.J. Winkler - F.I. Zeitlin (edd.), Nothing to Do With Dionysos? Athenian Drama in its Social Context, Princeton 1990, pp. 130-67 (già in J.P. Euben [ed.], Greek Tragedy and Political Theory, Los Angeles 1986, pp. 101-141).

\section{NOTE}

1. Ahl 1986; orientati ancora più decisamente in senso politico Dominik 1990 e 1994, McGuire 1990 e 1997. Letture negative anche in Hershkowitz 1995, 1998; Fantham 1997, 1999. L'interpretazione pessimista trova un precursore in Burck 1953, 1979.

2. Cf. Vessey 1973, pp. 307-16, spec. 314-6 (un cenno al parallelismo con Vespasiano e Domiziano a p. 315, n. 1 ; in n. 1 a p. 312 un riferimento alla clementia di Domiziano celebrata nelle Silvae). Positivi anche, prima e dopo Vessey, Rieks 1967, pp. 220-25; Helzle 1996, pp. 158 s.

3. Ahl 1986, p. 2896 (etichettato come 'pluralista', Ahl inclina verso un'interpretazione decisamente negativa di Teseo); Dominik 1990, pp. 87-92; 1994, pp. 93-98; cf. anche Davis 1994, p. 471.

4. Hardie 1993, pp. 46-8 (sulle strategie di closure nella Tebaide è tornato Hardie 1997, pp. 151-8, accentuando i contatti con tratti trionfali dell'Eneide). Vd. inoltre Feeney 1991, pp. 362-3; tra i 'pluralisti' la Braund classifica anche Henderson 1991 (cf. 1993).

5. Dominik 2005, p. 521. Gli argomenti di Ahl e di Dominik, già riecheggiati da Davis cit., sono riproposti ad es. da Dietrich 1999, pp. 44-5. Vd. inoltre Hershkowitz 1998, pp. 144-7; Lovatt 1999 (cf. n. 34 p. 135). 
6. Lovatt 1999.

7. Fantham 1999, pp. 226-32; Dietrich 1999; Pagán 2000; Markus 2003, 2004.

8. Ripoll 1998b, pp. 441-6, spec. 445 s.

9. Delarue 2000, pp. 368 ss., 372 ss.

10. Vd., su Teseo, Pollmann 2004, pp. 37-43 e passim nel commento.

11. McNelis 2007, cap. 6.

12. Ganiban 2007, cap. 9 (la citazione è da p. 229).

13. Sul concetto di negoziato, con cui il poeta rivendica la propria capacità di iniziativa e di proposta nei confronti del potere, vd. spec. Nauta 2002, Newlands 2002, Rosati $2008^{*}$.

14. Per la ricca bibliografia su questo noto passo rimando a Rosati $2008^{*}$, n. 1 .

15. Vd. Rosati $2008^{*}$, importante sul rapporto fra potere politico e potere letterario configurato nell'epilogo.

16. silv. 5, 3, 176-94 mox et Romuleam stirpem proceresque futuros / instruis inque patrum vestigia ducere perstas. / sub te Dardanius facis explorator opertae, / qui Diomedei celat penetralia furti, / crevit et inde sacrum didicit puer; arma probandis / monstrasti Saliis praesagumque aethera certis / auguribus; cui Chalcidicum fas volvere carmen, / 182a***** / cur Phrygii lateat coma flaminis, et tua multum / verbera succincti formidavere Luperci. / et nunc ex illo forsan grege gentibus alter / iura dat Eois, alter compescit Hiberas, / alter Achaemenium secludit Zeugmate Persen, / hi dites Asiae populos, hi Pontica frenant, / hi fora pacificis emendant fascibus, illi / castra pia statione tenent; tu laudis origo. / non tibi certassent iuvenilia fingere corda / Nestor et indomiti Phoenix moderator alumni / quique tubas acres lituosque audire volentem / Aeaciden alio frangebat carmine Chiron.

17. Vd. Gibson 2006 ad loc.

18. Parallelo il compiacimento del successo sperato presso i Romulei patres con la recitazione dell' Achilleide, in silv. 5, 2, 158 ss. nos fortior aetas / iam fugit; hinc votis tantum precibusque iuvabo. / ei mihi! sed coetus solitos si forte ciebo / et mea Romulei venient ad carmina patres, / tu deris, Crispine, mihi, cuneosque per omnes / te meus absentem circumspectabit Achilles. / sed venies melior (vatum non inrita currunt / omina), quique aquilas tibi nunc et castra recludit, / idem omnes properare gradus cingique superbis / fascibus et patrias dabit insedisse curules... (vd. Gibson 2006 al v. 160 per la scelta di coetus di Gronovius al posto del tradito questus di M).

19. Sulla recusatio vd. Nauta 2006; Rosati 2002. Sul De bello Germanico Courtney 1980, pp. 195-6; 1993, p. 360; Morton Braund 1996b a Iuv. 4, 72-118; Nauta 2002, p. 330.

20. Feeney 1991, p. 362; Hardie 1993, p. 48.

21. Ho studiato questo aspetto in Bessone 2006.

22. Ripoll 1998, p. 6, vede un contrasto fra la tragedia dei primi undici libri e la prospettiva epicoprovvidenzialistica del dodicesimo, che si allineerebbe al (presunto) ottimismo di Virgilio. Il concetto è più volte ribadito in Ripoll 1998b, ad es. p. 437; 439: “...le changement radical de climat entre la dernière partie de la Thébaïde et tout ce qui précède: l'abandon de l'ambiance tragique et du pessimisme psychologique sénéco-lucanien consacre le retour à un universe épique où les valeurs morales ne sont plus problématiques"; 444: “C'est en somme le retour de l'univers épique purifié et dépouillé de l'ambiguité morale qui entachait la guerre thébano-argienne, contaminée par la tragédie [...] Clementia liquide la tragédie, et Thésée ramène l'épopée".

23. Della vasta bibliografia sul concetto di clementia (per cui rimando a Malaspina $2005^{2}$ ) mi limito a ricordare qui, oltre a Adam 1970 e a Wallace-Hadrill 1981, alcuni lavori recenti: Konstan 2001 (cap. 3) e 2005; Griffin 2003.

24. Vd. Bessone 2008. Sul tema tornerò in un lavoro a parte. Sulla clementia nella Tebaide restaimportante, anche se va rivisto in alcuni aspetti, Burgess 1972; inoltre Morton Braund 1996, pp. 9-12; attento al rapporto col De clementia, ma non sempre convincente, Delarue 2000, pp. 109-11; Ripoll 1998b, p. 441 ss., spec. 445-6, dà invece un'interpretazione dichiaratamente apolitica; sulla clementia come soluzione privata alla crisi rappresentata nel poema vd. ora anche McNelis 2007, pp. 165, 177; una valutazione fortemente riduttiva del ruolo di Clementia e della 
clementia di Teseo nel finale (in quanto confuse con la misericordia) in Ganiban 2007, pp. 214 ss., spec. 219-22.

25. Come 'manifesto' del legame essenziale fra l'ideale etico rappresentato da Atene e la capacità

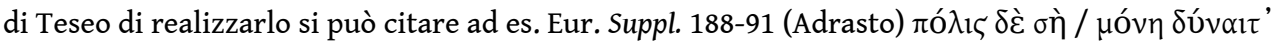

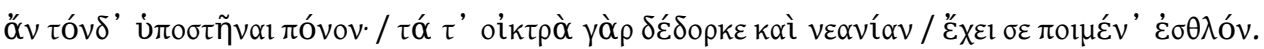

26. Vd., dopo la ricognizione di Reussner 1921, il giudizio sommario di Vessey 1973, p. 308; un cenno promettente, ma senza seguito, in Morton Braund 1996, p. 9 e n. 20; così Delarue 2000, p. 161; non più di una menzione in McNelis 2007, p. 160 e in Ganiban 2007, p. 223. Singoli contatti con le Supplici sono registrati nel commento di Pollmann 2004.

27. In questa direzione si muove ora, giudicando Teseo in base alla teoria stoica delle passioni, anche Ganiban 2007, ad es. p. 217: “Statius' Theseus is just as much a part of the epic's critique of Virgilian kingship as is the presentation of Oedipus and his sons, even though Theseus' actions achieve a positive result"; 219: "Theseus' clementia (i.e. misericordia) is just as much a part of the problematic political structure of the Thebaid's presentation of kingship as is crudelitas"; 222: "The words permotus and concitus express violent emotional upheaval - exactly what, on a Stoic reading, should not inform Theseus' decision to punish Creon, for he becomes the type of threatening and (potentially) irrational monarch from whom Clementia offers suppliants protection". Sul problema del rapporto tra clementia e misericordia tornerò in altra sede.

28. Lewis 1936, p. 55 (cit. da Vessey 1973, n. 1 p. 308). Cf. invece ancora Ganiban 2007, p. 223, sulla frettolosità di Teseo.

29. In Bessone 2008, che qui riprendo ed integro.

30. Vd. Zeitlin 1990 (= 1986), spec. p. 147. Cf. ora Morton Braund 2006.

31. Theb. 12, 698-708; vd. infra.

32. Dominik 1990, p. 93: "In the end the concentration in the narrative upon the negative consequences of a seemingly just war... serves to undermine considerably not only the ideal of such a war but also the surface protrayal of Theseus as a truly just king". Su Teseo e il iustum bellum, secondo la definizione di Cicerone nel De officiis, vd. invece Ripoll 1998b, pp. 430 ss.

33. Paduano 1966, pp. 199 s. e 203 ss.

34. Di Benedetto 1971, p. 163. La tragedia, rappresentata probabilmente nel 423 o 422 a.C., presuppone la sconfitta ateniese a Delio nel 424 a.C.

35. Di Benedetto 1971, pp. 156-7; importanti tutte le pp. 154-92.

36. Di Benedetto 1971, p. 163.

37. L'interpretazione della tragedia è vivacemente dibattuta: non sono mancati tentativi di letture ironiche e valutazioni negative del personaggio di Teseo, in un parallelismo interessante con la critica staziana (vd. Collard 1975, introd., pp. 23-31, e la rassegna di G. Heldmann in Hose 2005, pp. 255-81); di contro, si vedano in particolare Paduano 1966; Di Benedetto 1971, pp. 154-192; Bertelli 2003.

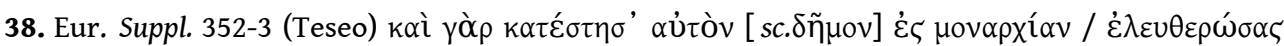

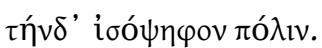

39. Cf. Raaflaub 2003.

40. Bertelli 2003. Cf. Morwood 2007, pp. 8-11.

41. Il contrasto ideologico tra i due personaggi ha un precedente nell'Edipo a Colono: cf. il discorso di Teseo in Soph. Oed.C. 904 ss.

42. Theb. 12, 481-511. Sul passo mi sono soffermata in Bessone 2008 e tornerò in un lavoro a parte.

43. Per la funzione di ammonimento e di deterrente attribuita nella cultura romana all'esempio negativo si può citare Hor. sat. 1, 4, 109 ss. 'nonne vides, Albi ut male vivat filius utque / Baius inops? magnum documentum, ne patriam rem / perdere quis velit' (cf. 128-9 'sic teneros animos aliena opprobria saepe / absterrent vitiis'). Per l'uso del termine nella storiografia moralistica vd. Bessone 2006, n. 2 a p. 113 (cf. Liv. praef. 10; 28, 21, 9; Tac. ann. 16, 33, 1). 
44. Cf. 11, 677-82 (Edipo) 'iamne vacat saevire, Creon? modo perfida regna / fortunaeque locum nostrae, miserande, subisti, / et tibi iam fas est regum calcare ruinas? / iam tumulis victos, socios iam moenibus arces? / macte, potes digne Thebarum sceptra tueri: / haec tua prima dies'.

45. Alla successione empia di Creonte al trono si contrappone l'esempio positivo dell'avvicendamento tra Anfiarao e l'indovino Tiodamante: 8, 294-8 is ubi intorto signatus vellere crinem / convenitque deis, / hilari per castra tumultu / vadit ovans ac, prima sui documenta, sacerdos / Tellurem placare parat: nec futile maestis / id visum Danais; Stazio lo illustra mediante una significativa similitudine con la successione nei regni orientali: vd. Hardie 1993 (essenziale sulla centralità di questo tema nell'epica), pp. 111 ss.

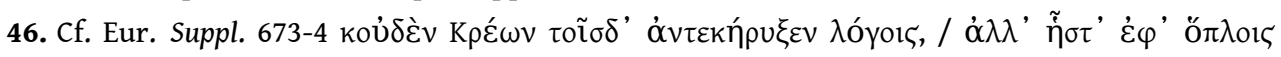
$\sigma \tilde{\mathrm{i}} \gamma \alpha$.

47. Cf. 7, 791-2 sidentis in tabem spectat acervos / et Magni numerat populos.

48. Cf. Eur. Suppl. 311, 377-80, 526.

49. Vd. Fantham 1992 ad loc.; Narducci 2004, p. 19. Cf. Lapidge 1979, spec. p. 361. Sull'uso del nesso (che varia il lucreziano foedera naturae) in Sen. Med. 335 e 606 vd. Fabre-Serris 2000.

50. Sul nesso tra politica e cosmologia già negli stoici antichi vd. Vogt 2008.

51. Mi sembra dunque inopportuno il commento di Ganiban 2007, p. 223: “Theseus' response consequently seems hasty, despite the fact that it is directed at Creon's nefas". Condivisibile invece Pollmann 2004 ad loc.

52. 12, 608 protinus; 611 continuo (cf. 614 ultroque); 640-1 raptim... breves; 649 praeceps; $661-4$ noctem adeo placidasque operi iunxere tenebras, / certamenque immane viris quo concita tendunt / agmina: quis visas proclamet ab aggere Thebas, / cuius in Ogygio stet princeps lancea muro; 709-11 Atticus at contra, iubar ut clarescere ruptis / nubibus et solem primis aspexit in armis, / desilit in campum.

53. Eur. Suppl. 229-37.

54. 12, 548-51 'non externa genus, dirae nec conscia noxae / turba sumus: domus Argos erat regesque mariti, / non utinam et fortes! quid enim septena movere / castra et Agenoreos opus emendare penates?', dove si coglie un'eco, e come un rovesciamento, della domanda-accusa di Teseo ad Adrasto in

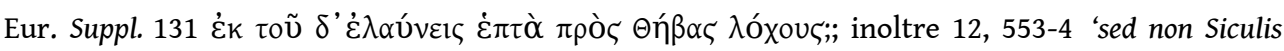
exorta sub antris / monstra nec Ossaei bello cecidere bimembres', che stride con la caratterizzazione 'titanica' dell'impresa di Capaneo nel decimo libro; vd. Vessey 1973, p. 312 e soprattutto Feeney 1991, n. 156 a p. 361: "Evadne is on thin ice in her claim that the Argives were not gigantesque monsters $(12,553-4)$; her husband was doing his best to break into this category (10, 849-52)"; cf. inoltre Delarue 2000, p. 163.

55. Theb. 12, 555 ss. 'mitto genus clarosque patres: hominum, inclute Theseu, / sanguis erant, homines, eademque in sidera, eosdem / sortitus animarum alimentaque vestra creati... (561) heu princeps Natura!...', da confrontare non solo per il concetto (Delarue 2000, pp. 166-8), ma anche per la formulazione con Sen. ep. 95, in particolare col $\$ 52$ Natura nos cognatos edidit, cum ex isdem et in eadem gigneret; haec nobis amorem indidit mutuum et sociabiles fecit [...] ex illius imperio paratae sint iuvandis manus. 53. Ille versus et in pectore et in ore sit: homo sum, humani nihil a me alienum puto. Habeamus in commune: <in commune> nati sumus.

56. Per il tiranno-fiera, assetato o compiaciuto del sangue, vd. Torre 1995; Bellincioni 1984, pp. 37-44. Cf. Sen. clem. 1, 11, 4 - 12, 2 Quid interest inter tyrannum ac regem (species enim ipsa fortunae ac licentia par est), nisi quod tyranni in voluptatem saeviunt, reges non nisi ex causa ac necessitate?'Quid ergo? non reges quoque occidere solent?'. Sed quotiens id fieri publica utilitas persuadet; tyrannis saevitia cordi est. Tyrannus autem a rege factis distat, non nomine [...] quis tamen umquam tyrannus tam avide humanum sanguinem bibit quam ille...?

57. Ampia disamina in Ripoll 1998b, pp. 432-40. Un esempio di giudizio negativo da ultimo in Ganiban 2007, p. 222 e n. 60: “While I agree that Theseus' ira does have a positive outcome (the defeat of (reon), nonetheless the phrase iusta ira represents the problematic nature of Theseus' 
clementia that can culminate in a "just" action but that is still based on destructive passions that could lead in the opposite direction - that is, to cruelty and crime".

58. Un passo in cui mi sembra difficile vedere "the apparent possession of Theseus by the angry dead" (Hardie 1993, p. 47).

59. Cf. anche Ripoll 1998b, pp. 434, 438. Iusta ira è anche quella di Tideo contro il tiranno predecessore di Creonte, Eteocle: un'ira giustificata, in particolare, dall'imboscata del re contro l'ambasceria dello stesso Tideo nel secondo libro; 7, 538 ss. hic iustae Tydeus memor occupat irae: / 'me potius, socii, qui fidum Eteoclea nuper / expertus, nec frater eram, me opponite regi, / cuius adhuc pacem egregiam et bona foedera gesto / pectore in hoc...'.

60. Sen. de ira 2, 6-14 (cf. 1, 12, 1).

61. Importante su questo tema Morton Braund-Gilbert 2003 (vd. anche l'Appendice II, Contextualizing Epic Ira Philosophically).

62. Sen. de ira 1, 11, 1 'Sed adversus hostes' inquit 'necessaria est ira'. Nusquam minus: ubi non effusos esse oportet impetus sed temperatos et oboedientes...; 1, 11, 8 (cf. 1, 12, 5; 1, 13, 3).

63. Vd. Malaspina $2005^{2}$ ad loc.

64. Cic. Tusc. 4, 43 Quid, quod iidem Peripatetici perturbationes istas quas nos extirpandas putamus, non modo naturalis esse dicunt, sed etiam utiliter a natura datas? Quorum est talis oratio: primum multis verbis iracundiam laudant, cotem fortitudinis esse dicunt, multoque et in hostem et in improbum civem vehementiores iratorum impetus esse...; 48-50.

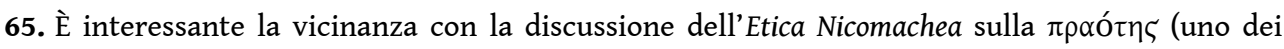
termini cui si sovrappone il latino clementia) come giusto mezzo nel dominio dell'ópүń e come uso controllato dell'ira nelle circostanze opportune e per il tempo opportuno (cf. $\delta \varepsilon \tilde{\imath})$ : Arist.

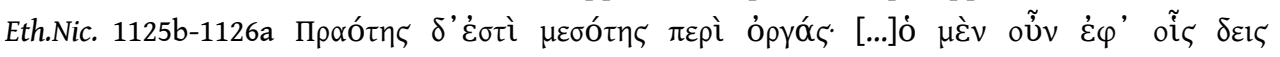

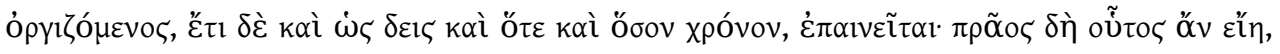

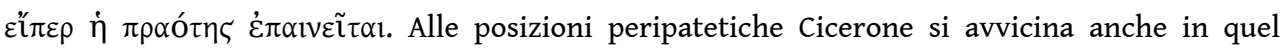
manifesto politico del buon governo che è l'epistola ad Quint.fr. 1, 1, al par. 38: ...resistendum esse iracundiae [...] quae quidem mihi virtus interdum non minor videtur quam omnino non irasci [...] moderari vero et animo et orationi cum sis iratus [...] etsi non est perfectae sapientiae, tamen est non mediocris ingeni.

66. Publil. 1.22 iracundiam qui vincit, hostem superat maximum; Ov. her. 3,85 vince animos iramque tuam, qui cetera vincis; Sen. de ira 1, 11, 5 iram ante vicit quam Hannibalem; Val. Max. 9.3.7 hostium quam irae fortior victor; vd. Gaertner 2005 a Ov. Pont. 1, 7, 48 victa sit ira (e cf. Plaut. Trin. 309 si ipse animum pepulit, dum vivit, victor victorum cluet).

67. Cf. i passi raccolti da Lechi 1988, p. 126 e n. 31: Pont. 1, 8, 69 ut iustam supprimat iram / Caesar; 2, 3, 61 ira quidem primo fuerat tua iusta; 2, 8, 76 iustaque quamvis est, sit minor ira dei; trist. 1, 2, 61 quamque dedit vitam mitissima Caesaris ira; trist. 5, 2, 55 ira quidem moderata tua est; Pont. 2, 9, 77 habuit moderatam vindicis iram; si aggiungano inoltre trist. 2, 27 ss. his precor exemplis tua nunc, mitissime Caesar, / fiat ab ingenio mollior ira meo. / illa quidem iusta est, nec me meruisse negabo... sed...; Pont. 1, 2, 87-8 ira viri mitis... 96 paene etiam merito parcior ira meo est.

68. Non mancano, naturalmente, interpretazioni in senso ironico e sovversivo di questa tentata conciliazione ovidiana tra ira e clementia (così, ad esempio, nel commento di Gaertner 2005 a Pont. 1); tuttavia, qualunque sia il grado di ironia che si vuol riconoscere al discorso di Ovidio, esso mostra la pertinenza e la rilevanza del tema della iusta ira nell'ambito delle discussioni sulla clementia imperiale.

69. Pollmann 2004 ad loc. cita, insieme a passi di Sallustio e Livio, anche quello di Ovidio, senza darvi particolare rilievo.

70. Vd. Hardie 1997, pp. 153-4 e Pollmann 2004 ad loc.

71. Analogo l'atteggiamento nei confronti di Cesare in Sen. de ira 2, 23, 4 ...quo rarior autem moderatio in regibus, hoc laudanda magis est. Fecit hoc et $C$. Caesar ille qui victoria civili clementissime usus est [...] Quamvis moderate soleret irasci, maluit tamen non posse; gratissimum putavit genus veniae 
nescire quid quisque peccasset. Quando si ha a che fare con i re, il vero compito è persuaderli a porre fine all'ira, come dimostra di sapere la Medea di Seneca: Sen. Med. 203 ss. difficile quam sit animum ab ira flectere / iam concitatum quamque regale hoc putet / sceptris superbas quisquis admovit manus, / qua coepit ire, regia didici mea.

72. Tutto il contesto è importante, per la cautela del ragionamento e per l'ammissione, come dato di partenza, di una illimitata possibilità del sovrano di abbandonarsi all'ira, che è solo il sovrano stesso a poter autolimitare: Sen. clem. 1, 5, 4 ss. Clementia... sed in regia, quo rarior, eo mirabilior. Quid enim est memorabilius quam eum cuius irae nihil obstat...ipsum sibi manum inicere et potestate sua in melius placidiusque uti...? Muliebre est furere in ira...

73. Il passo è citato da Pollmann 2004 ad loc.

74. Cf. Vinchesi 2001, introd., pp. 14 ss., 55 s. L'episodio (diversamente narrato in Livio e in Plutarco) è ricordato come esempio di misericordia anche da Cic. Verr. II, 2, 4; il paradosso della gioia dei vinti è similmente sottolineato in Val. Max. 5, 1, 4 Age, M. Marcelli clementia quam clarum quamque memorabile exemplum haberi debet! Qui captis ab se Syracusis in arce earum constitit, ut urbis modo opulentissimae, tunc adflictae fortunam ex alto cerneret. Ceterum casum eius lugubrem intuens fletum cohibere non potuit. Quem si quis ignarus viri aspexisset, alterius victoriam esse credidisset. Itaque, Syracusana civitas, maxima clade tua aliquid admixtum gratulationis habuisti, quia, si tibi incolumem stare fas non erat, leniter sub tam mansueto victore cecidisti.

75. Sia Stazio che Silio potrebbero tenere presente il modello virgiliano: in Verg. Aen. 12, 583 ss. exoritur trepidos inter discordia civis: / urbem alii reserare iubent et pandere portas / Dardanidis ipsumque trahunt in moenia regem; / arma ferunt alii et pergunt defendere muros andrebbe infatti considerata la possibilità di intendere regem (come talvolta inteso in passato: cf. Forbiger $1875^{4} \mathrm{ad}$ loc.) in riferimento ad Enea anziché a Latino (con trahunt in senso conativo: "tentano di attirare"). In moenia sembra infatti indicare ingresso, meglio che avvicinamento (e segue due espressioni che indicano appunto il far entrare i Troiani; il verso precedente è incorniciato da urbem e portas, questo sarebbe incorniciato da quelli che, nella città e nelle porte, si vogliono far entrare); anche trahunt si adatta forse meglio al tentativo di far entrare Enea che non a quello di "trascinare" Latino alle mura; soprattutto, ipsum mette in contrasto i Dardanidae con il loro capo (la disposizione dei due termini a cornice del verso lo sottolinea); tutti insieme, i vv. 584-5 formano un tricolon ascendente (ipsum contrasta con Dardanidis, ma esprime anche climax: "addirittura" il loro re). Stazio realizzerebbe così nel finale della Tebaide la possibilità che il finale dell'Eneide aveva contemplato e lasciato irrealizzata: la città (quasi) vinta vorrebbe aprirsi ad accogliere il capo nemico.

76. Vd. Pollmann 2004 a 582 anus hospita. Quello di ospite è un ruolo tipico di Teseo, che caratterizza già le imprese più antiche dell'eroe (accolto festosamente come liberatore da mostri

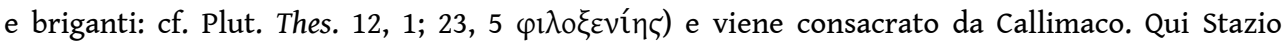
riecheggia la declinazione ovidiana del motivo, nell'episodio di Acheloo: Ov. met. 8, 550 ss. 'succede meis' ait, 'inclite, tectis, / Cecropide'; 560-1 adnuit Aegides 'utor' que, 'Acheloe, domoque / consilioque tuo' respondit, et usus utroque est. / pumice multicavo nec levibus atria tofis / structa subit; 570 amnis Acarnanum, laetissimus hospite tanto (cf. Theb. 12, 784 ss.).

77. Tra i molti studi ricordo Bertelli - Gianotti 1987; Walker 1995; Calame 1996; Mills 1997; Aloni 2003.

78. Hagedorn 2004, cap. 3, pp. 75-101 (si veda la citazione di Ahl 1986 nella n. 2 a p. 76).

79. Vd. Morton Braund 1996, p. 13 e n. 33.

80. Sulla sincerità del dolore di Teseo per la morte del padre, causata dalla sua dimenticanza, non lascia dubbi anchel'impiego dell'exemplum ad illustrare il dolore di Claudio Etrusco in silv. 3, 3, 176-80, benché qui l'espressione falsis deceperat... velis, riferita a Teseo stesso, ed eventualmente il tràdito periuria (che però Courtney, Laguna-Mariscal e Shackleton Bailey correggono con Polster in per Sunia... litora: per mantenere il testo traditoè necessario correggere litora in litore, come già nei recentiores) sottolineino l'oggettiva responsabilità dell'eroe: vv. 179-80 haud alitergemuit per 
Sunia Theseus / litora, qui falsis deceperat <A>egea velis (così Courtney e Laguna-Mariscal 1992, di cui vd. il commento ad loc.).

81. Ciò non toglie che contatti interessanti (ma, direi, privi di un potenziale destabilizzante) possano crearsi tra le due figure: è notevole che il ravvedimento di Edipo sui cadaveri dei figli in 11, 605 ss. ricordi in qualche tratto la disperazione di Teseo per la morte di Ippolito, innocente, nella Fedra di Seneca; l'intenzione di appiattire l'uno sull'altro i due personaggi mi sembra però estranea alla costruzione staziana.

82. Cf. Cat. 64, 100 quanto saepe magis fulgore expalluit auri, / cum saevum cupiens contra contendere monstrum / aut mortem appeteret Theseus aut praemia laudis!

83. Cat. 64,$58 ; 123 ; 135 ; 248$. Un peso eccessivo al contatto con Catullo dà anche McNelis 2007, pp. 172-4 (nonostante qualche accento più smorzato in chiusa, cf. p. 174 "Though we need not privilege the vision of Theseus contained in Catullus 64...").

84. Per la fortuna di questa tradizione in ambito romano cf. Ov. Pont. 4, 10, 71 ss. e Iuv. 1, 1-2, rispettivamente su Albinovano Pedone e su un certo Cordo, autori di Teseidi.

85. Vd. Hagedorn 2004, pp. 96 s.

86. Notevoli anche alcuni tratti di ironia nei confronti di Teseo nel racconto della lotta fra Lapiti e Centauri fatto da Nestore in met. 12, 210-535 (cf. 359-60 sed procul a telo Theseus veniente recessit / Pallados admonitu: credi sic ipse volebat con Galasso 2000 ad loc.; 344-5, su cui vd. infra). Sulla (mancata) ‘Teseide’ di Ovidio nelle Metamorfosi vd. Mack 1988, pp. 136-41; Gildenhard-Zissos 2004, p. 68.

87. Bessone 1988, pp. 141-4; 2002, spec. p. 192 e n. 28.

88. Il personaggio senecano, criticato per la scarsa consistenza drammatica (vd. Timpanaro 1981, p. 129), andrebbe maggiormente considerato per il suo rilievo ideologico.

89. Vd. Dingel 1974, pp. 125-128.

90. Plat. Gorg. 525 c-d; Resp. 10, 615 c - 616 b.

91. Cf. Fitch 1987 e Billerbeck 1999 ai vv. citt.; Malaspina 2003, pp. 274-5, 286, 300.

92. L'ammonimento funziona dunque in senso opposto rispetto a quello pronunciato dall'empio Phlegyas in Verg. Aen. 6, 620: un passo che Seneca presuppone e rovescia, riabilitando in modo significativo la figura di Teseo; cf. Aen. 6, 617-20 sedet aeternumque sedebit / infelix Theseus, Phlegyasque miserrimus omnis / admonet et magna testatur voce per umbras: / "discite iustitiam moniti et non temnere divos". Nel testo senecano l'empia impresa tentata da Teseo per fedeltà all'amico Piritoo resta in ombra; si veda come Stazio stesso, sulla scorta di una tradizione consolidata, la presenti come prova di amicizia fedele, persino attraverso le parole di Plutone, in Theb. 8, 53-4 'me Pirithoi temerarius ardor / temptat et audaci Theseus iuratus amico'.

93. Sui tratti anomali di questa battaglia rispetto alla tradizione epica vd. Esposito 2002.

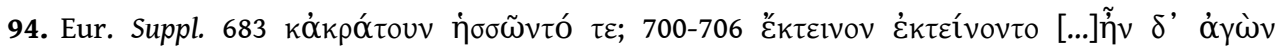
iøó $\rho$ ротоక.

95. Narducci 2002, pp. 192 ss.

96. Il confronto già in Pollmann 2004.

97. A questa similitudine si richiama quella successiva, che illustra lo scatenarsi della battaglia; anche nel settimo libro una coppia di similitudini metteva in contrasto il momentaneo effetto sulle truppe della supplica di Giocasta e la ripresa dello slancio bellico per l'esortazione di Tideo (7, 529-33; 559-63). Una tecnica narrativa analoga è impiegata di nuovo a creare suspense e a ritardare, per un istante, il realizzarsi della guerra: una nuova guerra, questa volta legittima, ma che ancora una volta l'autore epico sembrerebbe non voler narrare.

98. Vd. Dominik 1994, pp. 92-8. Sulle similitudini con Marte nell'epica flavia in generale vd. Ripoll 1998b, 164-90 (su Stazio spec. 176-8, con valutazione positiva).

99. L'effetto della vista di Teseo sui nemici ricorda quello sugli abitanti di Maratona, dopo

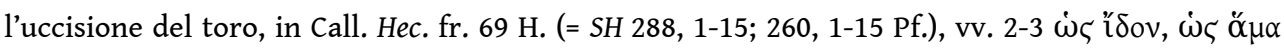

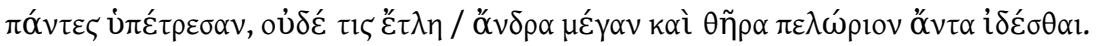


100. Verg. Aen. 12, 324 ss., cf. 328 ss. multa virum volitans dat fortia corpora leto [...], 331 ss. qualis apud gelidi cum flumina concitus Hebri / sanguineus Mavors clipeo increpat atque furentis / bella movens immittit equos, illi aequore aperto / ante Notos Zephyrumque volant, gemit ultima pulsu / Thraca pedum circumque atrae Formidinis ora / Iraeque Insidiaeque, dei comitatus, aguntur: / talis equos alacer media inter proelia Turnus / fumantis sudore quatit, miserabile caesis / hostibus insultans; spargit rapida ungula rores / sanguineos mixtaque cruor calcatur harena. Vd. Traina 1998, pp. 99-100; Pöschl 1977³, pp. 150-51.

101. Sil. 17, 486-90 ipse super strages ductor Rhoeteius instat, / qualis apud gelidum currus quatit altior Hebrum / et Geticas solvit ferventi sanguine Mavors / laetus caede nives, glaciemque Aquilonibus actam / perrumpit stridens sub pondere belliger axis. Vd. Ripoll 1998b, p. 179.

102. Errata l'interpretazione di plebeio in Pollmann 2004 ("plebeio does not refer to the pursued enemy"): vd. infra.

103. Cf. Aen. 12, 481-3 haut minus Aeneas tortos legit obvius orbes / vestigatque virum et disiecta per agmina magna / voce vocat.

104. Theb. 12, 741-51, cf. 743 ss. ...et triplici confisos robore gentis / Alcetidas fratres, totidem quos eminus hastis / continuat; ferrum consumpsit pectore Phyleus, / ore momordit Helops, umero transmisit Iapyx. / iamque et quadriiugo celsum petit Haemona curru, / horrendumque manu telum rotat: ille paventes / obliquavit equos; longo perlata tenore / transiit hasta duos, sitiebat vulnera nec non / tertia, sed medio cuspis temone retenta est. L'uccisione in sequenza dei tre fratelli (triplici... continuat) ricorda la triplice prodezza di Enea in Aen. 12, 513 ss. illeTalon Tanaimque neci fortemque Cethegum, / tris uno congressu, et maestum mittit Oniten..., mentre il sollevamento del masso richiama quello di Turno, Aen. 12, 896-7 saxum... ingens, / saxum anticum ingens, 904 tollentemve manu saxumve immane moventem.

105. Notevole il parallelismo con l'episodio di Tideo, che trascura avversari "minori" e cerca invano di scontrarsi con il solo Eteocle (il tiranno predecessore di Creonte), ma "tuttavia" (tamen, $8,696)$ fa intanto strage di nemici, con una crudezza del tutto estranea a Teseo: 8, 671, 677 ss.,684 ss.; 689-99 (cf., nella similitudine, nec cura... illum, illum...). La variazione su quella matrice narrativa sottolinea che il tentativo di Tideo è stato una cattiva anticipazione del tirannicidio di Teseo.

106. Silio riprende insieme Stazio e Virgilio (con interessanti correzioni) nell'aristia conclusiva di Scipione: Pun. 17, 491 ss. iamque ardore truci lustrans fortissima quaeque / nomina obit ferro. claris spectata per orbem / stragibus occumbit late inter tela iuventus [...]509 ss. verum ubi cunctari taedet dispersa virorum / proelia sectantem et leviori Marte teneri, / omnes in causam belli auctoremque malorum / vertere iam vires tandem placet. Hannibal unus / dum restet, non, si muris Carthaginis ignis / subdatur caesique cadant exercitus omnis, / profectum Latio. contra, si concidat unus, / nequiquam fore Agenoreis cuncta arma virosque. / illum igitur lustrans circumfert lumina campo / rimaturque ducem. iuvat in certamina summa / ferre gradum, cuperetque viro concurrere tota / spectante Ausonia. celsus clamore feroci / provocat increpitans hostem et nova proelia poscit.

107. Vd. Hardie 1993, p. 46; 1997, p. 153; Morton Braund 1996, pp. 3-4. Si veda anche la giustificazione della propria causa in Aen. 12, 565 'Iuppiter hac stat' e in Theb. 12, 644-7 'hac omnem divumque hominumque favorem / Naturamque ducem coetusque silentis Averni / stare palam est; illic Poenarum exercita Thebis / agmina et anguicomae ducent vexilla sorores' (con Pollmann 2004 ad loc.);

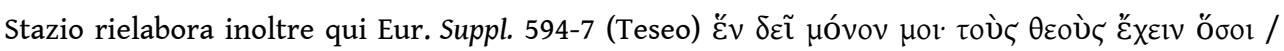

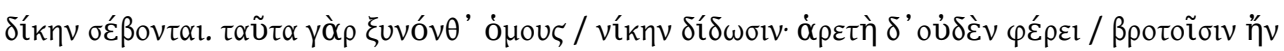

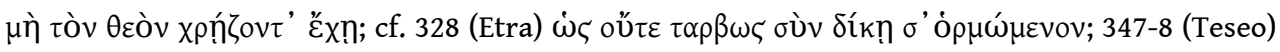

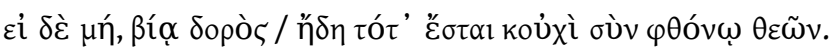

108. Cf. già l'annuncio dell'araldo di Teseo in Suppl. 670-2 '

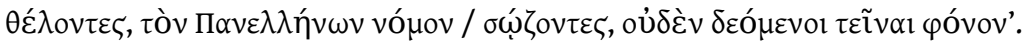

109. Vd. Di Benedetto 1971, p. 168. 
110. Con queste parole, secondo Di Benedetto 1971, pp. 158 ss., Euripide avrebbe invitato gli Ateniesi, in vista dell'elezione degli strateghi, a scegliere un moderato, dopo che il bellicismo di Cleone aveva causato il disastro di Delio del 424 a.C.

111. Svet. Caes. 75 Acie Pharsalica proclamavit, ut civibus parceretur; Flor. 2, 13, 50 Voces quoque obequitantis acceptae, altera cruenta, sed docta et ad victoriam efficax 'miles faciem feri!' altera ad

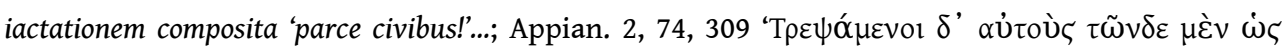

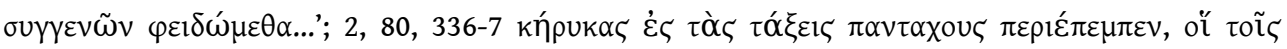

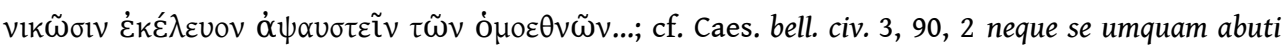
militum sanguine neque rempublicam alterutro exercitu privare voluisse. Inoltre Luc. 7, 318 ss. 'vos tamen hoc oro, iuvenes, ne caedere quisquam / hostis terga velit: civis qui fugerit esto. / sed dum tela micant, non vos pietatis imago / ulla nec adversa conspecti fronte parentes / commoveant; vultus gladio turbate verendos...', con Leigh 1997, pp. 216-7; Narducci 2002, p. 216 e nn. 86-7.

112. Su magnanimus detto di Teseo in 12,795 , e di Domiziano in 12,814 , vd. Morton Braund 1996, p. 18.

113. L'immagine del leone è, anzi, impiegata da Apollo per caratterizzare la mancanza di ع̌ $\lambda \varepsilon \_\varsigma$ di Achille in Il. 24, 31-45.

114. Cf. Phaedr. 1, 29, 10; Babr. 107; Romul. 22 Thiele; vd. Weinreich $1931=1973$ e Citroni 1975 a Mart. 1, 22.

115. Vd. Keudel 1970, pp. 63 ss., 74-7.

116. Cito il testo secondo l'edizione di Hall; Ricci 2001 stampa invece, con Birt, gaudent... nobiliore fame (cf. Stat. Theb. 7, 531 gaudentque in corpore capto). Il soggetto astratto fames è notevole e andrà conservato (cf. Mart. 1, 22, 3 s. nec gaudet tenui sanguine tanta sitis); si potrebbe forse pensare a correggere nobiliore in nobilior: si avrebbe così un nesso interessante e si restituirebbe al leone la nobiltà che è il suo tratto distintivo. L'espressione nec nisi bellantis gaudet cervice iuvenci ricalca Theb. 8, 596 nec nisi regnantis cervice recumbere tauri; sul rapporto con Ovidio vd. Ricci ad loc. e Ricci 1998. Al v. 29, dove i mss. sono divisi tra calent e valent, Ricci 2001 stampa vident, congettura di Tandoi (Barth correggeva in volunt).

117. Mart. 1, 6; 14; 22; 48; 51; 60; 104. Vd. Weinreich 1928, pp. 90-103; Citroni 1975, intr. a 1, 6 e comm. ai singoli epigrammi; Lorenz 2002, pp. 126-34, ma soprattutto Nauta 2002, pp. 402-12; importante Rosati 2006, pp. 41-52, spec. 45-8. Sul tema vedi ora anche Coleman 2006, passim (Intr., LXXIX ss.; comm. a Mart. spect. 12 [10], 20 [17], 21 [18], 33 [30 S, L; 29 H]).

118. Rosati 2006, pp. 45-52.

119. La contrapposizione fra leone e cani è anche in 1 , 48, 7-8 si vitare canum morsus, lepus improbe, quaeris, / ad quae confugias ora leonis habes; quella fra prede piccole e grandi (lepri e tori) è invece in 1, 48, 1-2; 1, 51 non facit ad saevos cervix, nisi prima, leones. / quid fugis hos dentes, ambitiose lepus? / scilicet a magnis ad te descendere tauris / et quae non cernunt frangere colla velint. / desperanda tibi est ingentis gloria fati: / non potes hoc tenuis praeda sub hoste mori; 1, 60 intres ampla licet torvi lepus ora leonis, / esse tamen vacuo se leo dente putat. / quod ruet in tergum vel quos procumbet in armos, / alta iuvencorum volnera figet ubi? / quid frustra nemorum dominum regemque fatigas? / non nisi delecta pascitur ille fera; 1, 104, 12 ss. ...haec transit tamen, ut minora, quisquis / venatus humiles videt leonum, / quos velox leporum timor fatigat. / demittunt, repetunt, amantque captos, / et securior est in ore praeda, / laxos cui dare perviosque rictus / gaudent et timidos tenere dentes, / mollem frangere dum pudet rapinam, / stratis cum modo venerint iuvencis. / haec clementia non paratur arte, / sed norunt cui serviant leones. Gli epigrammi 1,6 e 1, 14 sono invece incentrati sulla clemenza del leone come emanazione miracolosa di quella del sovrano.

120. La matrice 'politica' dell'immagine potrebbe essere compresente anche nella similitudine per Atreo in Sen. Thy. 732-41: il tiranno che non risparmia (731), dopo i due più grandi, neppure il figlio più piccolo del fratello è come un leone che, fatta strage di tori, pulsa fame / non ponit iras: hinc et hinc tauros premens / vitulis minatur dente iam lasso inpiger (734-6).

121. Kytzler 1962, pp. 150-2. 
122. Theb. 7, 670 ss. qualis ubi primam leo mane cubilibus atris / erexit rabiem et saevo speculatur ab antro / aut cervum aut nondum bellantem fronte iuvencum, / it fremitu gaudens, licet arma gregesque lacessant / venantum, praedam videt et sua volnera nescit: / sic tum congressu Capaneus gavisus iniquo / librabat magna venturam mole cupressum.

123. Theb. 8, 570 ss. ac prima in faciles grassatus cuspide turmas / arma refert sociis et in agmina fida peracta / caede redit. sic Hyrcana leo Caspius umbra / nudus adhuc nulloque iubae flaventis honore / terribilis magnique etiamnum sanguinis insons, / haud procul a stabulis captat custode remoto / segne pecus teneraque famem consumit in agna; 8, 592 ss. sic ait, et belli maiora ad praemia mente / ducitur: innumeris veluti leo forte potitus / caedibus imbelles vitulos mollesque iuvencas / transmittit: magno furor est in sanguine mergi / nec nisi regnantis cervice recumbere tauri (cf. 583-4 audacem non ense nec hasta / dignatus).

124. Cf. Theb. 8, 93 ss. '...oro, minas stimulataque corda remulce, / neve ira dignare hominem et tua iura timentem [...] 119-122 sed pectora flectas / et melior sis, quaeso, deis. si quando nefanda / huc aderit coniunx, illi funesta reserva / supplicia: illa tua, rector bone, dignior ira'.

125. Meno significativo l'uso dell'immagine, a illustrare il temporaneo placarsi delle truppe argive di fronte alla supplica di Giocasta, in Theb. 7, 527-33 tumidas frangebant dicta cohortes, / nutantesque virum galeas et sparsa videres / fletibus arma piis. quales ubi tela virosque / pectoris impulsu rabidi stravere leones, / protinus ira minor, gaudentque in corpore capto / securam differre famem: sic flexa Pelasgum / corda labant, ferrique avidus mansueverat ardor: qui il piacere di saziare la fame sulla preda è solo rimandato (bene Smolenaars 1994 ad loc.).

126. Cf. Morton Braund-Gilbert 2003, pp. 256-7.

127. Sugli aspetti negativi di virtus nella Tebaide vd. Fantham 1995.

128. Vd. Harrison 1991 ad loc. Nella Tebaide il composto compare anche in 9,785 'dum ferus hic vero desaevit pulvere Mavors'.

129. Verg. Aen. 9, 339-45 impastus ceu plena leo per ovilia turbans / (suadet enim vesana fames) manditque trahitque / molle pecus metumque metu, fremit ore cruento. / nec minor Euryali caedes; incensus et ipse / perfurit ac multam in medio sine nomine plebem/ Fadumque Herbesumque subit Rhoetumque Abarimque / ignaros...

130. Vd. Venini 1970 ad loc.

\section{RIASSUNTI}

Il ruolo di Teseo e della clementia nel finale della Tebaide si scontrano interpretazioni opposte del poema, in una polarizzazione che riproduce il dibattito critico sull'Eneide. Letture sovversive e pessimistiche, $\mathrm{o}$, al contrario, ottimistiche e celebrative, oscurano la complessità di una chiusa in cui convivono esemplarità e pessimismo, come nelle Supplici di Euripide. La Tebaide è un discorso sul potere che inscrive in sé la coscienza di una crisi; la frattura fra i primi undici libri e il dodicesimo spezza forma epica e discorso politico in due parti complementari e in tensione fra loro: all'epica del nefas si contrappone infine un'epica del vincitore, a una spedizione maledetta una guerra giusta, alla degenerazione del potere assoluto l'apparizione di una regalità clemente; la proposta ideologica del finale sta al resto del poema come il De clementia sta alle tragedie di Seneca: rappresenta uno sforzo di ricostruzione dei valori su cui si fonda l'istituto imperiale. Ripensando in termini attuali l'opposizione fra Atene e Tebe nelle Supplici, Stazio trasforma il confronto euripideo fra democrazia e tirannide in un contrasto fra re e tiranno, fra clementia e 
inclementia regum, fra Teseo e Creonte. La costruzione del personaggio di Teseo mette in ombra la tradizione catulliana, selezionando i tratti che fanno dell'eroe nazionale ateniese un simbolo politico, adottato dai più vari discorsi del potere. L'associazione di Teseo con la sovranità clemente e con la punizione dei tiranni ha un precedente nell'Hercules furens di Seneca. La moderazione di Teseo in battaglia è illustrata con un paradigma animale (il leone mite con la preda) tradizionale nelle esortazioni alla clementia.

\section{INDICE}

Mots-clés : Critica staziana e critica virgiliana, negoziato tra poesia e potere, epilogo della Tebaide, Silvae 5-3, speculum principis, Virgilio-Eneide, Euripide-Supplici, Teseo, cle

\section{AUTORE}

\section{FEDERICA BESSONE}

Università di Torino

federica.bessone@unito.it 